Policy Research Working Paper 2978

\title{
The Epidemiological Impact of an HIV Vaccine on the HIV/AIDS Epidemic in Southern India
}

\author{
Nico J. D. Nagelkerke \\ Sake J. De Vlas
}

The World Bank

Development Research Group

Public Services

February 2003 
Policy Research Working Paper 2978

\begin{abstract}
The potential epidemiological impact of preventive HIV vaccines on the HIV epidemic in Southern India is examined using a mathematıcal deterministic dynamic compartmental model. Various assumptions about the degree of protection offered by such a vaccinc, the extent of immunological response of those vaccinated, and the duration of protection afforded are explored. Alternative targeting strategies for HIV vaccination are simulated and compared with the impact of conventional prevention interventions in high-risk groups and the general population. The impact of disinhibition (increased risk behavior due to the presence of a vaccine) is also considered.
\end{abstract}

Vaccines that convey a high degree of protection in a share of or all of those immunized and that convey lifelong ummunity are the most effective in curbing the HIV epidemic. Vaccones that convey less than complete protection may also have substantial public health impact, but disınhibition can easily undo their effects and they should be used combined with conventional prevention efforts. Conventional interventions that target commercial sex workers and therr clients to increase condom use can also be highly effective and can be implemented immediately, before the arrival of vaccines.

This paper-a product of Public Services, Development Research Group-is part of a research project "The Economics of an HIV/AIDS Vaccine in Developing Countries: Potential Impact, Cost-Effectıveness, and Willingness to Pay" sponsored by the European Commission and the World Bank. The project was launched in response to recommendations of the World Bank's AIDS Vaccine Task Force. Copies of this paper are avalable free from the World Bank, $1818 \mathrm{H} \mathrm{Street} \mathrm{NW,}$ Washington, DC 20433. Please contact Hedy Sladovich, mail stop MC3-31 1, telephone 202-473-7698, fax 202-522-1154, emall address hsladovich@worldbank.org. Policy Research Working Papers are also posted on the Web at http:// econ.worldbank.org. The authors may be contacted at nico.nagelkerke@rivm.nl or devlas@mgz.fgg.eur.nl. February 2003. (27pages)

The Policy Research Workmg Paper Sertes dissemunates the findungs of work $m$ progress to encourage the exchange of ideas about development issues An objective of the sertes ts to get the fundmgs out quackly, even if the presentatoms are less than fully polished. The papers carn' the names of the authors and should be cated accordingly. The findings, mterpretations, and comclustons expressed in this paper are enttrely those of the authors. They do not necessarly represent the tuew of the World Bank, ats Executne Directors, or the countrics they represent. 


\title{
The Epidemiological Impact of an HIV Vaccine on the HIV/AIDS Epidemic in Southern India
}

\author{
N. J. D. Nagelkerke \\ Corresponding author: N.J.D.Nagelkerke@lumc.nl
}

S. J. De Vlas

devlas@mgz.fgg.eur.nl

Address: Department of Public Health, Erasmus MC, University Medical Center Rotterdam, P.O. Box 1738, 3000 DR Rotterdam, Netherlands. The authors thank Prabhat Jha, Martha Ainsworth, and two anonymous reviewers for their invaluable suggestions and comments. This paper is a product of the research project on "The economics of an HIV/AIDS vaccine in developing countries: Potential impact, cost-effectiveness and willingness to pay", sponsored by the European Commission and the Development Research Group of the World Bank (Martha Ainsworth, task manager). The project was launched in response to recommendations of the World Bank's AIDS Vaccine Task Force. The findings, interpretations, and conclusions expressed in this paper are entirely those of the authors and do not necessarily represent the views of the World Bank or the European Commission, its Executive Directors, or the countries they represent. 



\section{Contents}

1. Introduction ................................................................................................................................ 1

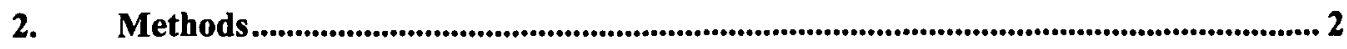

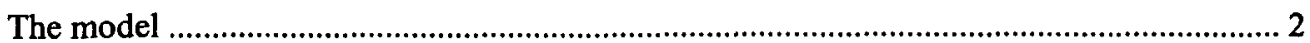

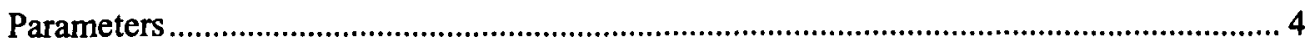

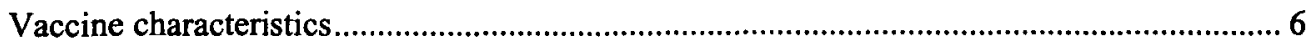

Targeting strategies :................................................................................................................ 6

Conventional interventions for comparison ........................................................................... 7

Disinhibition (increase in risky behavior) ............................................................................. 8

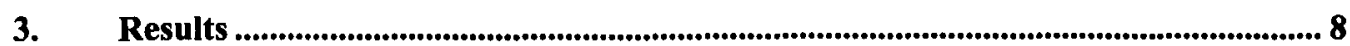

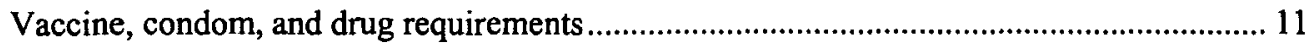

4. Discussion................................................................................................................................ 13

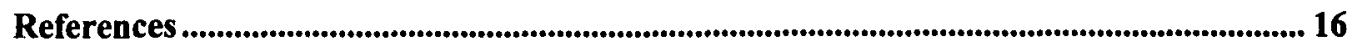

Annex 1. Technical description of the model, including a graphical representation.......... 19

\section{Tables}

Table 1. Model parameters (no interventions active) ......................................................................

Table 2. Adult HIV prevalence in 2033 under seven scenarios, with and without disinhibition .9

Table 3. Annual number of vaccinations (millions), by vaccination scenario

Figures

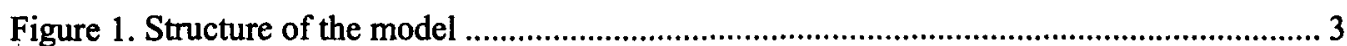

Figure 2a. Epidemiological impact of targeting a preventive HIV vaccine to the general population, compared with CSW and STI interventions, South India .............................. 10

Figure 3a. Cumulative number of vaccinations required for targeting the general population . 12

Figure 3b. Cumulative number of vaccinations required for targeting high-risk groups.........................12

\section{Acronyms}

$\begin{array}{ll}\text { ART } & \text { Anti-retroviral therapy } \\ \text { CSW } & \text { Commercial sex worker } \\ \text { HRG } & \text { High-risk group } \\ \text { IDU } & \text { Intravenous drug user } \\ \text { MSM } & \text { Men who have sex with men } \\ \text { MTCT } & \text { Mother-to-child transmission } \\ \text { NACO } & \text { National AIDS Control Organisation } \\ \text { STI } & \text { Sexually-transmitted infections }\end{array}$





\section{Introduction}

India's current HIV-1 seroprevalence rate of slightly less than 1 percent of adults, or approximately 4 million HIV infected individuals, is bound to increase. In the Southern states of India (Andhra Pradesh, Karnataka, Maharashtra and Tamil Nadu), adult HIV-1 prevalence of approximately 2 percent is already observed (National AIDS Control Organisation website). In some districts, it is already over 4 percent. The four states together account for over 75 percent of all Indian HIV infections, even though they have less than 30 percent of the adult population (Government of India 2002). The engine of the Indian epidemic is almost certainly heterosexual transmission from vulnerable groups, chiefly commercial sex workers (CSWs) and their clients.

HIV infection in vulnerable groups has grown rapidly in India, where control of HIV and sexually transmitted infections (STI) used to be poor. The conditions for further rapid growth are also in place: paid sex is common, rates of STI are high, male mobility is high, rates of condom use in risky sex are low, and rates of male circumcision-a presumed protective factor-are low. Even an increase to a modest 5 percent infection level in India, the lower end of the African epidemics, in 2025, would represent 25-30 million infected adults and, over the next 25 years, approximately 50 million cumulative HIV-1 infections and 40 million cumulative deaths. This is twice the cumulative number of global deaths due to HIV/AIDS over the past two decades.

This paper models the potential epidemiological impact of preventive HIV vaccines on the HIV/AIDS epidemic in Southern India, using a mathematical deterministic dynamic compartmental model. In the second section, we describe the basic assumptions and workings of the model and the characteristics of the vaccines and targeting strategies for an HIV vaccination campaign that are modeled. Various assumptions about the degree of protection offered by such a vaccine, the extent of immunological response in those vaccinated, and the duration of protection afforded are explored. In the third section, we present the results, comparing the epidemiological impact of alternative vaccines and targeting strategies to that of conventional prevention strategies aimed at raising condom use among high-risk groups (sex workers and their client) and improving the syndromic treatment of STIs. The impact of disinhibition (increased risk behavior due to the presence of a vaccine) is also 'considered. The final section summarizes the results and points to implications for HIV/AIDS prevention policies.

The best long-term hope for control of the HIV epidemic may be a preventive HIV vaccine. Until one is developed, scaling up high impact preventive interventions can reduce the growth of the epidemic. There is an urgent need to develop new candidate vaccines, but also a need to plan the considerable program requirements in introducing new vaccines and in fitting them into other prevention strategies. An AIDS vaccine will greatly help to reduce HIV/AIDS, but it will not be a panacea. Because of the possibility of behavior reversals and an imperfect vaccine (e.g., one that confers 
only partial protection, or no protection at all in some of those vaccinated), other preventive efforts must be continued, if not expanded.

\section{Methods}

This paper complements a recent paper by Stover and others (2002) in which two HIV/AIDS epidemiological models (the Imperial College Model and IwgAIDS) were used to explore the effects of a potential vaccine in Thailand, Uganda, and Zimbabwe. We extend a mathematical model of HIV-1 transmission in Southern India, using methods previously developed for Working Group Five of the Commission on Macroeconomics and Health (Nagelkerke and others 2002). We use the ModelMaker program, version 3.0.3 (AP Benson 1993-97), for implementing our model.

\section{The model}

The model is a dynamic, deterministic compartmental model. The main features of the model that are pertinent to the vaccine exercise are described in Figure 1. The boxes represent compartments, or states, that individuals can be in and the arrows show the flow of individuals between compartments. Each compartment shown has been implemented in duplicate, for men and women separately. Individuals move between gender-specific compartments. For example, for women there are two groupings, CSWW and low-risk women. Each of these two groups is split into several groups based on their infection and immunization status:

- those uninfected and immunized,

- those uninfected and not immunized, and

- those who are infected (in three sub-groups, early stage, late state, and AIDS).

There is no age structure in the model as used for the purpose of projecting the impact of an HIV vaccine, with the exception that the model only concerns the sexually active adult population. ${ }^{1}$ It assumes that the epidemic is primarily heterosexual, driven by commercial sex, and that unsafe sex work is widespread and contributes substantially to the spread of the infection. CSW and their clients were assigned separate compartments to reflect this assumption. In India, approximately 80 percent of STI are first-generation infections derived from sex work, so this seems reasonable (Rodrigues and others 1995). Early female HIV infections occurred predominantly in $\mathrm{CSW}$; infection in monogamous women is probably linked to their husbands having visited a CSW (Gangakhedkar and others 1997, Pais 1996).

1 The model also incorporates mother-to-child transmission (MTCT, "vertical transmission") and an intervention ("nevirapine") to reduce this. However, as we are mainly interested in adult prevalence, which is not affected by MTCT, this is not considered here. A formal description of an earlier and more complete version of the model is available on the Internet (Nagelkerke and others 2001). 
Figure 1. Structure of the model

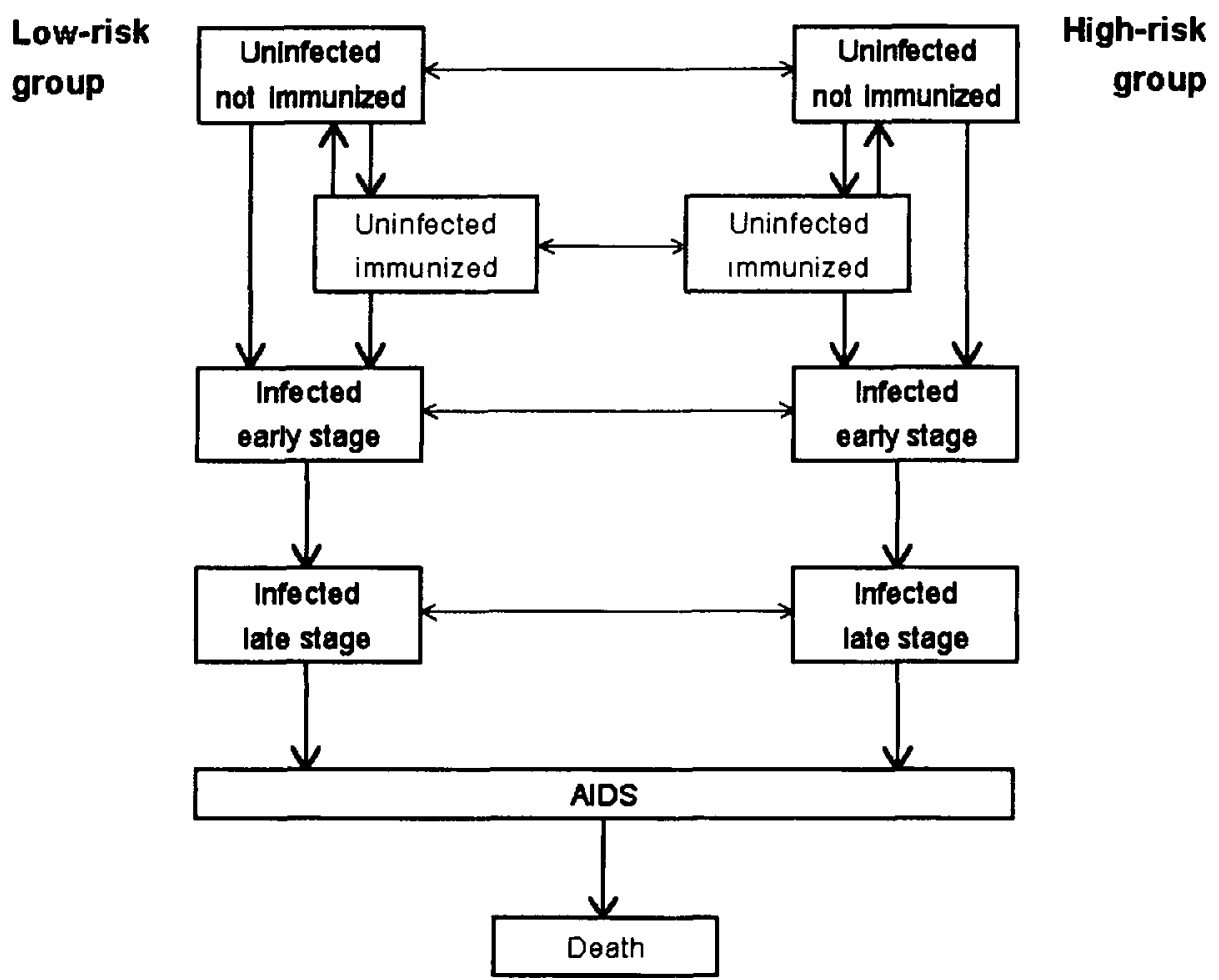

Individuals are "born into" the low-risk uninfected category of their gender and may move to and from high-risk groups (female CSWs and their male clients). In addition to dying from AIDS, they may die from other causes or "age" out of the sexually active age group. High-risk groups may infect low-risk groups (e.g., their current steady partners), including newly acquired low-risk (steady partners), for example, when they get married. The HIV disease process is broken down into three stages: early, late, and AIDS. ${ }^{2}$

The model includes neither transmission between men who have sex with men (MSM) nor transmission due to intravenous drug use (IDU). Both occur in India, but it is believed that they account for a minority of all transmissions. The role of MSM and IDU transmission and interaction with the heterosexual epidemic may be small, although IDU is an important mode of HIV transmission in the Northeastern state of Manipur (the main exception). Appendix 1 provides a formal technical description of the model, including a graphical representation.

2 The three stages of AIDS in the model facilitate modeling the impact of anti-retroviral therapy (ART) targeted at patients in different stages of HIV disease progression. ART is not among the interventions considered in this study, however. 


\section{Parameters}

In setting the parameters of the model, demographic data from South India were used where available; otherwise data from whole of India were used. A recent study conservatively estimates that there are at least 2 million CSW in India, each having on average-very conservatively-two clients per day, and that their clients number approximately 30 million (i.e., slightly over 10 percent of the adult male population) (Venkataramana and Sarada 2001). This suggests that each client may have some 50 CSW contacts annually. Based on the results of the recent nationwide behavioral survey commissioned by the National AIDS Control Organization (NACO), on others' estimates that over 40 percent of all CSWs work in the four Southern states, and on the higher prevalence of HIV in Southern India, we assumed that approximately 20 percent of all adult males are clients of CSW at any one time (NACO 2002).

Estimates of the rates of becoming a high-risk individual and transitioning back to the low-risk category are not available. From the fact that most studies find the mean age (and age-range) of sex workers to be low (often around 23 years), it follows that the rate of leaving the profession must be high. We chose 20 percent annually for this rate. We took half this value for the transition rate of from client to non-client. Rates of becoming a client can then be derived from the number of clients and the rate of becoming low-risk. For women we also introduced a demand factor, i.e., low-risk women's rate of becoming a CSW was modeled as a function of the demand for sex work.

The average duration from infection to AIDS is the sum of the average duration of the early and late stages; we assumed four years in each of the two stages, resulting in an average duration of HIV infection of eight years.

Modeling by the National Intelligence Council (2002) has suggested that the HIV/AIDS epidemic in India, would result in up to 25 million people living with HIV/AIDS by 2010 , i.e., an adult HIV prevalence of approximately 5 percent. However, as Southern India appears to be the worst-hit part of the subcontinent, our model corresponds to a scenario in which prevalence grows from its current level of approximately 2 percent of the sexually active population to an equilibrium prevalence of almost 8 percent.

Table 1 gives the (baseline) parameters used for the model: parameters were chosen to reflect conditions in the four Southern Indian states of Andhra Pradesh, Karnataka, Maharashtra, and Tamil Nadu combined. With this choice of parameters, a 2 percent HIV adult prevalence in 2001 was obtained. This prevalence would gradually increase to 7.5 percent in 2033 in the absence of any interventions. While not comparable to the prevalence encountered in many parts of Sub-Saharan Africa, this size of the epidemic would have devastating effects on Indian society and its socioeconomic development. 
Table 1. Model parameters (no interventions active)

\begin{tabular}{|c|c|c|}
\hline Parameter & Description (where relevant) & Value \\
\hline aidsrate & Annual rate of developing AIDS from late stage HIV & 0.25 \\
\hline Brate & Birth rate & 0.085 \\
\hline cr_before & Contact rate between clients and CSW & 50 \\
\hline Cust & Rate at which low-risk men become CSW-clients & 0.04 \\
\hline Femgr & Rate of growth adult female population & 0.021 \\
\hline Fmrisk & $\begin{array}{l}\text { Female to male HIV transmission risk during CSW-client } \\
\text { contact }\end{array}$ & 0.0036 \\
\hline HIVprog & Rate of HIV progression from early to late stage & 0.25 \\
\hline init_frac_cli & Initial (1998) fraction of adult men who are CSW clients & 0.2 \\
\hline init_frac_csw & Initial (1998) fraction of adult women who are CSW & 0.013 \\
\hline init_inf_cli & Initial (1998) clients HIV prevalence & 0.07 \\
\hline init_inf_csw & Initial (1998) CSW HIV prevalence & 0.25 \\
\hline init_inf_fem & Initial (1998) low-risk adult female HIV prevalence & 0.005 \\
\hline init_inf_men & Initial (1998) low risk adult males HIV prevalence & 0.005 \\
\hline init_pop_female & Initial female aduit population & $70,000,000$ \\
\hline init_pop_male & Initial male adult population & $70,000,000$ \\
\hline Leak & Transmission parameter high-risk to low-risk & 0.075 \\
\hline loss_immun & Rate (annual) of loss of vaccine induced immunity & 0 \\
\hline Malegr & Rate of growth of adult male population & 0.022 \\
\hline Marrate & Marriage rate & 0.058 \\
\hline Mfrisk & $\begin{array}{l}\text { Male to female HIV transmission risk during CSW-client } \\
\text { contact }\end{array}$ & 0.0052 \\
\hline Muaids & Death rate AIDS patients & 1 \\
\hline Muhiv_kids & Death rate HIV infected children & 0.25 \\
\hline Muneg & Death rate HIV-adults & 0.026 \\
\hline Mupos & Death rates (non-HIV) HIV+ adults & 0.028 \\
\hline Prof & $\begin{array}{l}\text { Parameter controlling proclivity of low risk women to become } \\
\text { CSW }\end{array}$ & 0.004 \\
\hline stabfactor & $\begin{array}{l}\text { Parameter on transmission between newly wed discordant } \\
\text { couples }\end{array}$ & 100 \\
\hline Startyr_condom_CSW & $\begin{array}{l}\text { Startyear (+1998)focussed intervention among CSW (use } \\
\text { condoms) }\end{array}$ & 35 \\
\hline Startyr_std & Startyear (+1998) Mwanza style STI control & 35 \\
\hline Startyr_vaccin & Startyear vaccine intervention & 35 \\
\hline STD_effect & $\begin{array}{l}\text { Effect of STI control on transmission ( } 1=\text { no effect, } \\
0=\text { transmission interrupted) }\end{array}$ & 0.7 \\
\hline Uncust & Rate CSW clients become low-risk men & 0.1 \\
\hline Unprof & Rate CSW become low-risk women & 0.2 \\
\hline Unprot_after & $\begin{array}{l}\text { Level of CSW-client non-use of condoms after focused } \\
\text { intervention }\end{array}$ & 0.25 \\
\hline Unprot_before & Same. Before intervention & 0.5 \\
\hline Vaceff & Level of vaccine protection, $0=100 \%, 1=0 \%$ & 0 \\
\hline Vactake & Proportion of vaccinated who respond & 0.5 \\
\hline Vtrate & Mother-to-child (i.e. vertical) HIV transmission rate & 0.33 \\
\hline w1 & Relative infectiousness early stage $\mathrm{HIV}+$ & 1 \\
\hline w2 & Relative infectiousness late stage HIV+ & 1 \\
\hline
\end{tabular}

Note: The model has additional parameters for estimating the impact of anti-retroviral therapy; these are not presented, as they are not relevant to modeling the impact of an AIDS vaccine. 
We compare the epidemiological impact over the period 1998-2033 of four different vaccines, defined by the levels of two parameters:

- Level of protection. The reduction in HIV susceptibility in those giving an effective immunological response to the vaccine. We consider two levels- -50 percent and 100 percent.

- Level of immune response. The percentage of those vaccinated who have an immunological response to the vaccine. We consider two levels- 50 percent and 95 percent - of those vaccinated. The vaccine has no protective effect on the remaining 50 percent (or 5 percent) receiving the vaccine who have no immune response to it.

We use the term "vaccine efficacy" to mean the product of the level of protection and level of immune response - that is, the average protection afforded to an average vaccinated person. Thus, a vaccine of 50 percent average efficacy in the population could be defined as either: (a) a vaccine conveying 100 percent protection to half of those vaccinated (50 percent immune response); or (b) 50 percent protection to everyone who is vaccinated (100 percent immune response) or (c) some other combination of protection and immune response that yields an average efficacy of 50 percent. $^{3}$

We assume that vaccines would become available in 2008, which is the earliest time vaccines would become available for general use if current development efforts prove successful, and that vaccines would provide (for those conferred any protection) immunity for at least 25 years (or vaccine recipients would be revaccinated sufficiently often to simulate this duration of immunity). In addition, we explored the effects of waning of vaccine efficacy by showing the impact of the "best" vaccine considered here ( 100 percent protection conferred to 95 percent of those vaccinated), if protection lasted on average 3 years. Following loss of vaccine-induced immunity, vaccine recipients move back to the compartments of susceptibles, from where they may be recruited for vaccination again.

\section{Targeting strategies}

We examine the impact of these vaccines of differing levels of efficacy using two different targeting scenarios with different assumptions on coverage:

3 Stover and others (2002) refer to vaccines that convey 100 percent protection to a share of those vaccinated as "take" vaccines (example (a) in the text) and those that convey partial protection to all who are vaccinated "degree" vaccines (example (b) in the text). They show that the epidemiological impact of a vaccine with a given average efficacy in a population is highly dependent on whether efficacy is achieved through "take" or "degree." This distinction between "take" and "degree" type effectiveness is not relevant for a vaccine with 100 percent efficacy (that is, complete protection of all who are vaccinated), as they are equivalent. Stover and others do not model the impact of vaccines with both partial protection and partial immune response, such as example (c) in the text, though their impact presumably would be somewhere between the impact of "take" and "degree" type vaccines for a given level of effectiveness. 
High risk group targeting (HRG). Both CSWs and their clients are targeted. Annually, 75 percent of those eligible (i.e. belonging to the target population and not yet immunized) would be vaccinated. This would result in an average coverage rate (proportion of the groups vaccinated) of approximately 90 percent.

Population targeting (POP). Every sexually active adult is equally targeted regardless of behavioral risk group. At the time the vaccine becomes available, a 2-year vaccination campaign is launched that succeeds in reaching 25 percent of the target population of susceptibles (HIV negative, not immune) annually. This is followed by an indefinite period during which 5 percent of the target population is vaccinated annually. This leads to an equilibrium situation in which approximately 50 percent of the sexually active population has been vaccinated. The initial 2 -year vaccination campaign is included to reach that 50 percent coverage level quickly.

\section{Conventional interventions for comparison}

As an HIV vaccine has not yet been developed and as a point of comparison, we also modeled the epidemiological impact of two conventional HIV prevention interventions:

A focused CSW intervention. The objective of this intervention is to increase condom use in CSW-client contacts. Focused interventions have proven to be very effective in increasing condom use in this context. This reduces HIV transmission among sex workers and clients, but also in the general population, because of the "core" role of these high-risk groups in spreading infection to the rest of the population (Hethcote and York 1984, Jha and others 2001, World Bank 1997). Many peermediated CSW intervention programs in India and Africa have shown increases in condom use of 80 percent or more among those reached (Bhave and others 1995, Jana and others 1998, Jana and Singh 1995, Moses and others 1991). We conservatively assumed that the intervention reduces the percentage of unprotected contacts from 50 to 25 percent. We were also conservative in not assuming an additional reduction in the risk of transmission per CSW-client contact through a reduction in STI prevalence, although this may well be the case.

Syndromic treatment of STIs. Epidemiological studies support the hypothesis that STIs are associated with increased HIV susceptibility and infectiousness. However, confounding makes it difficult to reliably estimate these cofactor effects from observational studies (Korenromp and others 2001). Three experimental studies have been carried out to date, one in Tanzania and two in Uganda. STI management, through improved treatment of patients with symptomatic STI infections, has proven to be effective in a controlled community trial in Mwanza, Tanzania, with an approximate 40 percent reduction in HIV transmission (Grosskurth and others 1995). STI management was based on a syndromic approach to symptomatic cases. It was applied to a rural area in a non-targeted way. People with asymptomatic infections were not treated. However, the failure of a similar intervention in a trial in Masaka, Uganda, to replicate this success (reported at the AIDS conference in Barcelona), and the lack of success in 
Rakai, Uganda, to reduce HIV transmission through a program that offered mass treatment for STIs to the population has sparked debate about the efficacy of such interventions in slowing HIV transmission (Gray and others 1999, Hitchcock and Fransen 1999, Hudson 2001, Korenromp and others 2000, Kvale 1999, Matthys and Boelaert 1999, Nicoll and others 1999). We nevertheless assumed for the purposes of this modeling exercise that HIV transmission would decrease by 30 percent across the board (males, females, high-risk, low-risk). Arguably, this is a strong simplification of reality and requires averaging over partnerships with and without STI. In reality, the average effect of the intervention may also vary among risk categories (e.g., CSW and other women), depending on factors that are largely unknown, such as the uptake of the intervention. No effects of the intervention on sexual behavior were assumed. Note that the way this 30 percent reduction is achieved is irrelevant for our predictions. Increasing condom use in the general population could be equally effective. As both interventions use existing technologies, they were assumed to start in 2003.

\section{Disinhibition (increase in risky behavior)}

We explore whether disinhibition-that is, an increase in risky behavior associated with the availability of an HIV vaccine-could nullify or reverse the impact of the vaccine. Disinhibition has been observed in high-risk gay men in response to the availability of anti-retroviral therapy (Katz and others 2002, Ostrow and others 2002, Stolte and others 2001, Stolte and Coutinho 2002). All models were run in the presence of a strong disinhibition effect, that is, assuming that condom use between CSWs and clients dropped from 50 percent (assumed to have increased already from very low levels in response to other prevention efforts) prior to the availability of vaccines to nil (0 percent). For comparison (adult) HIV prevalence in 2033 (the last year of the simulation) was used.

\section{Results}

Table 2 shows the effect of the different interventions on long run (2033) adult HIV prevalence. Conventional prevention programs begin in 2003 and vaccine interventions in 2008.

All vaccine scenarios show a decline in HIV prevalence. Generally, a high degree of protection appears to be more important than a high "take" rate. Disinhibition (i.e. condoms are no longer used during CSW-clients) has the potential of undoing much of the vaccine benefits, and may even aggravate the epidemic. However, our assumed extreme disinhibition effect of total abandonment of condom use, may be unlikely to happen, as condoms also provide protection against conventional sexually transmitted infections, an advantage that CSWs may be keen to keep. Targeting highrisk groups tends to be more effective than targeting the general population (at least at the levels considered). For the best vaccine considered (scenario 4), the impact appears to be similar, perhaps due to "over-vaccination" of high-risk groups (both clients and CSWs have a high vaccine coverage). 
Table 2. Adult HIV prevalence in 2033 under seven scenarios, with and without disinhibition"

\begin{tabular}{|c|c|c|c|c|c|c|}
\hline & \multicolumn{2}{|l|}{$\begin{array}{r}\text { Scenario } \\
\end{array}$} & \multicolumn{4}{|c|}{ Adult HIV prevalence in 2033 (percent) } \\
\hline \multirow[t]{2}{*}{$\mathbf{0}$} & \multirow{2}{*}{$\begin{array}{l}\text { Baseline } \\
\text { Conventional } \\
\text { interventions }\end{array}$} & \multirow[b]{2}{*}{$\begin{array}{c}\text { Protection } \\
\text { (percent) }\end{array}$} & \multicolumn{4}{|c|}{7.5} \\
\hline & & & & & & \\
\hline 1 & $\begin{array}{l}\text { CSW condom } \\
\text { intervention }\end{array}$ & $75^{b}$ & & & & \\
\hline \multirow[t]{3}{*}{2} & STI syndromic treatment & $30^{c}$ & & & & \\
\hline & \multirow{2}{*}{ Vaccine scenarios } & \multirow{2}{*}{$\begin{array}{l}\text { Efficacy } \\
\text { (percent) }\end{array}$} & \multicolumn{2}{|c|}{$\begin{array}{l}\text { Targeted to high-risk groups } \\
\text { (HRG) }\end{array}$} & \multicolumn{2}{|c|}{$\begin{array}{c}\text { Targeted to general } \\
\text { population (POP) }\end{array}$} \\
\hline & & & $\begin{array}{l}\text { No } \\
\text { disinhibition }\end{array}$ & Disinhibition & $\begin{array}{l}\text { No } \\
\text { dlsinhibition }\end{array}$ & Disinhibition \\
\hline 3 & $\begin{array}{l}100 \% \text { protection, } 50 \% \\
\text { response, } 25 \text { years } \\
\text { duration }\end{array}$ & 50 & 1.0 & 3.3 & 1.9 & 4.8 \\
\hline 4 & $\begin{array}{l}100 \% \text { protection, } 95 \% \\
\text { response, } 25 \text { years } \\
\text { duration }\end{array}$ & 95 & 0.6 & 1.4 & 0.6 & 2.1 \\
\hline 5 & $\begin{array}{l}50 \% \text { protection, } 95 \% \\
\text { response, } 25 \text { years } \\
\text { duration }\end{array}$ & 47.5 & 2.9 & 9.5 & 3.2 & 8.5 \\
\hline 6 & $\begin{array}{l}50 \% \text { protection, } 50 \% \\
\text { response, } 25 \text { years } \\
\text { duration }\end{array}$ & 25 & 3.7 & 10.3 & 4.6 & 10.0 \\
\hline 7 & $\begin{array}{l}100 \% \text { protection, } 95 \% \\
\text { response, } 3 \text { years } \\
\text { duration }\end{array}$ & 95 & 1.5 & 5.7 & 5.0 & 10.5 \\
\hline
\end{tabular}

a. Decline in condom use in commercial sex from $50 \%$ to zero.

b. Increase in protection from $50 \%$ to $75 \%$ among CSW-client contacts.

c. Reduction in transmission probability.

Figures $2 a$ and $2 b$ show the impact of the different interventions (without disinhibition) on HIV prevalence over the period 2003-2033. Note that a highly effective vaccine (scenario 4, 100 percent protection for 95 percent of those vaccinated) appears to be by far the most effective method to bring down HIV prevalence quickly, much faster than conventional prevention programs. The latter, however, have the advantage that their implementation could start immediately. 
Figure 2a. Epidemiological impact of targeting a preventive HIV vaccine to the general population, compared with CSW and STI interventions, South India

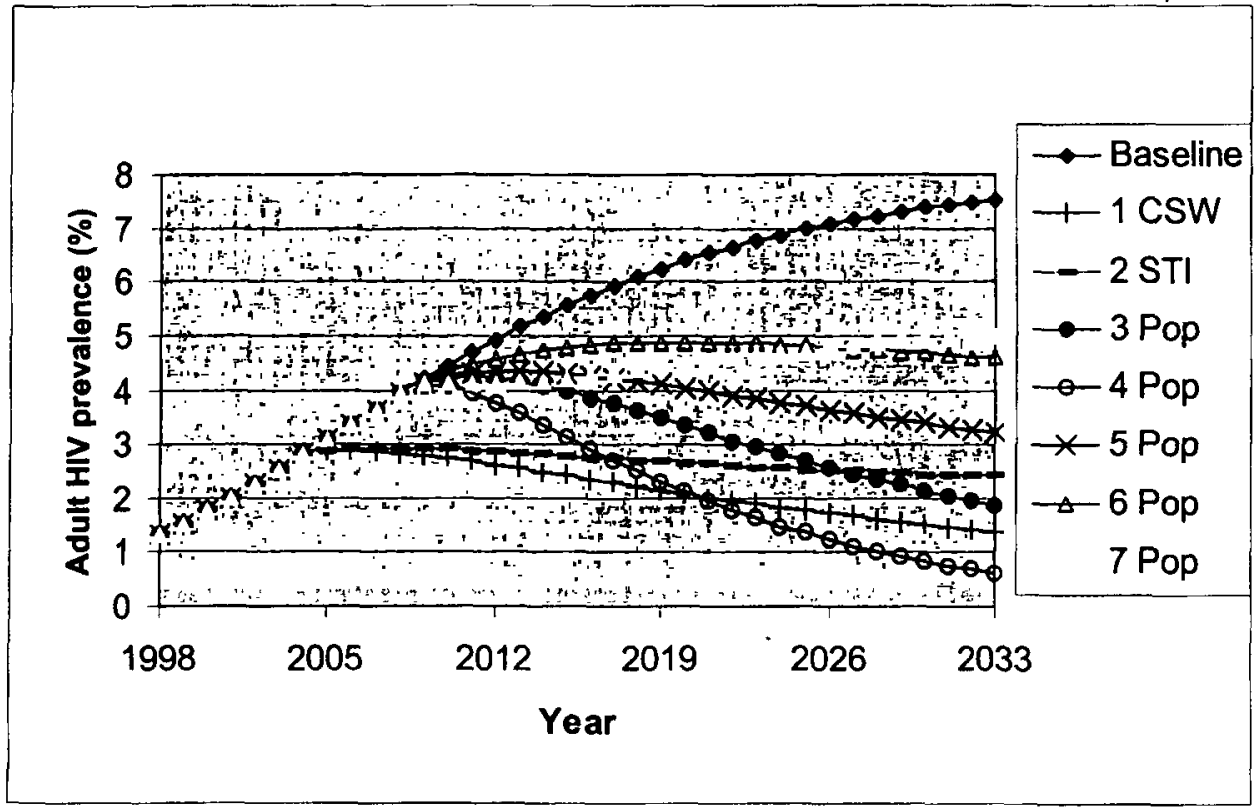

Note: Vaccines target approximately 50 percent of the general population; scenarios defined in Table 2.

Figure 2b. Epidemiological impact of targeting a preventive HIV vaccine to the high-risk population, compared with CSW and STI interventions, South India

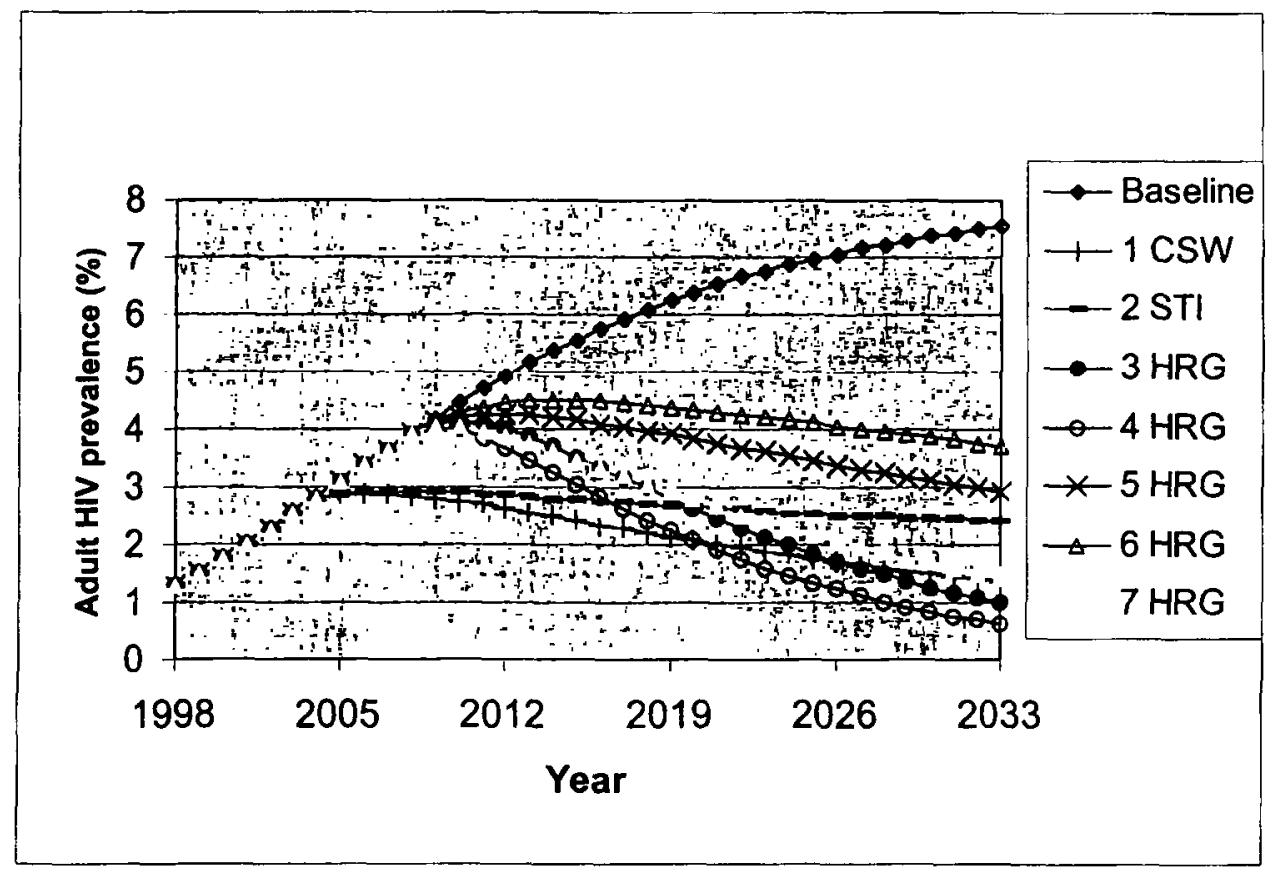

Note: Vaccines target approximately 90 percent of CSWs and clients; scenarios defined in Table 2. 
Vaccine, condom, and drug requirements

Figures $3 a$ and $3 b$ show the cumulative number of vaccinations needed under different strategies, assuming that those who are already HIV-positive are not vaccinated. Targeting high-risk groups typically requires substantially fewer vaccine doses than targeting the general population, at a similar or higher impact. Thus, unless the costs of targeting high risk groups are extremely high, targeting high-risk groups should be typically several times more cost-effective than targeting the general population. Also, to achieve reasonably high vaccination coverage for the general population, we assumed that a very intensive two-year vaccination campaign would "kick-start" vaccination coverage. This would put enormous strains on production facilities and other infrastructure and may be difficult to implement. The annual number of vaccinations implied by each of the targeted and general population strategies are in Table 3-including both the "kick-start" phase and the "maintenance" phase.

Costs follow from the costs to set up and maintain the infrastructure and of course the cost per vaccination, at present unknown. Even targeting only high-risk populations may require hundreds of millions of vaccine doses over a 25-year period. However, this is less than the number of childhood vaccinations given over that period and, unless the vaccine is very expensive (over US\$100, say), this would definitely seem affordable.

The number of condoms needed for a focused intervention for high-risk groups is easy to calculate. We assumed that approximately 20 percent of sexually active adult men would be clients, and that they have - on average-50 CSW contacts annually. We (optimistically, but based on NACO's sexual behavior surveys) assumed that approximately half of these contacts are already protected by condoms obtained from other sources (NACO 2002). Thus, to increase condom use to 75 percent, 13 additional condoms per client, or approximately 3 per adult male, would be required annually.

The amount of drugs and their costs for an STI control program are hard to predict. In addition to current prevalence and incidence of STIs, knock-on effects in terms of a reduction in transmission and a consequent decline in incidence may yield long-term savings in costs. For Mwanza, the annual per-capita costs of running am STI program were estimated to be $\$ 0.39$ (Gilson and others 1997). 
Figure 3a. Cumulative number of vaccinations required for targeting the general population, South India

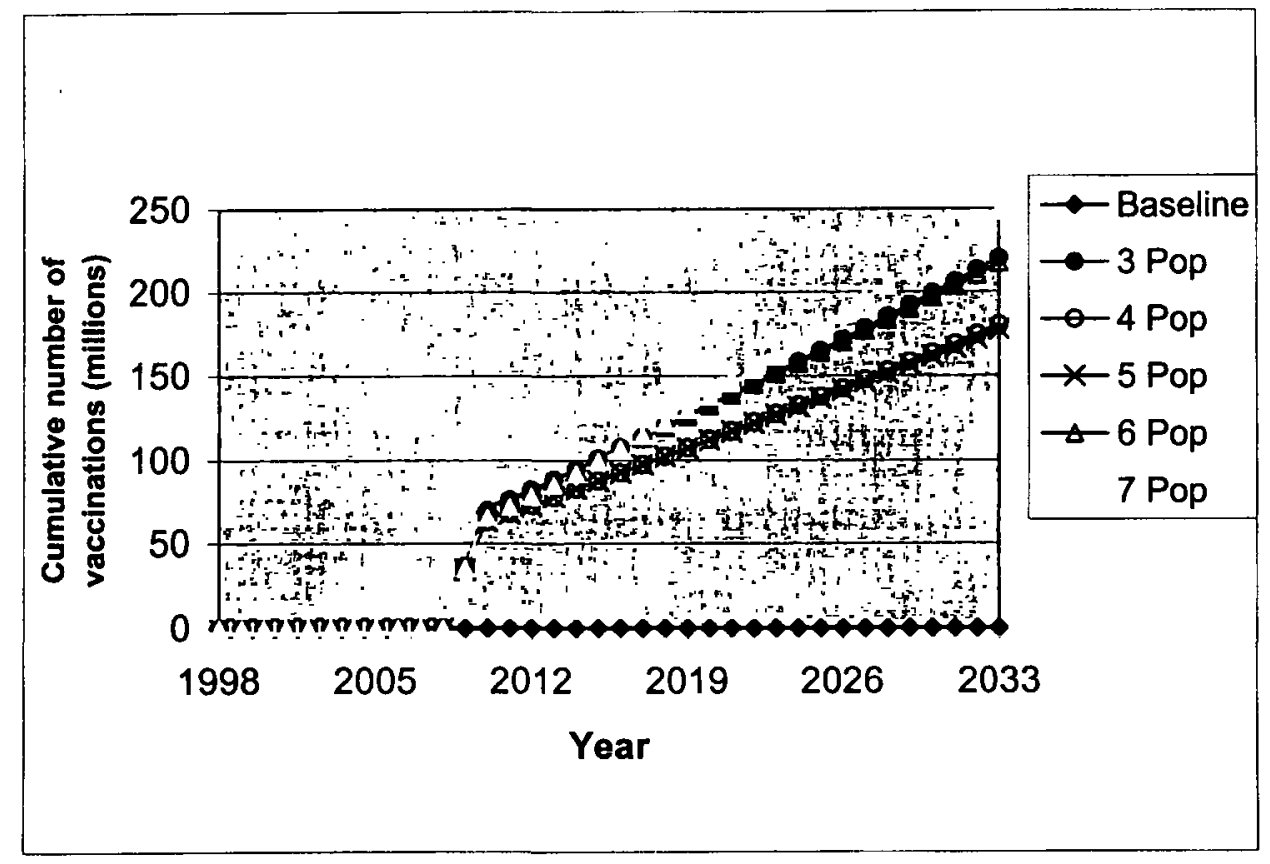

Figure 3b. Cumulative number of vaccinations required for targeting high-risk groups, South India

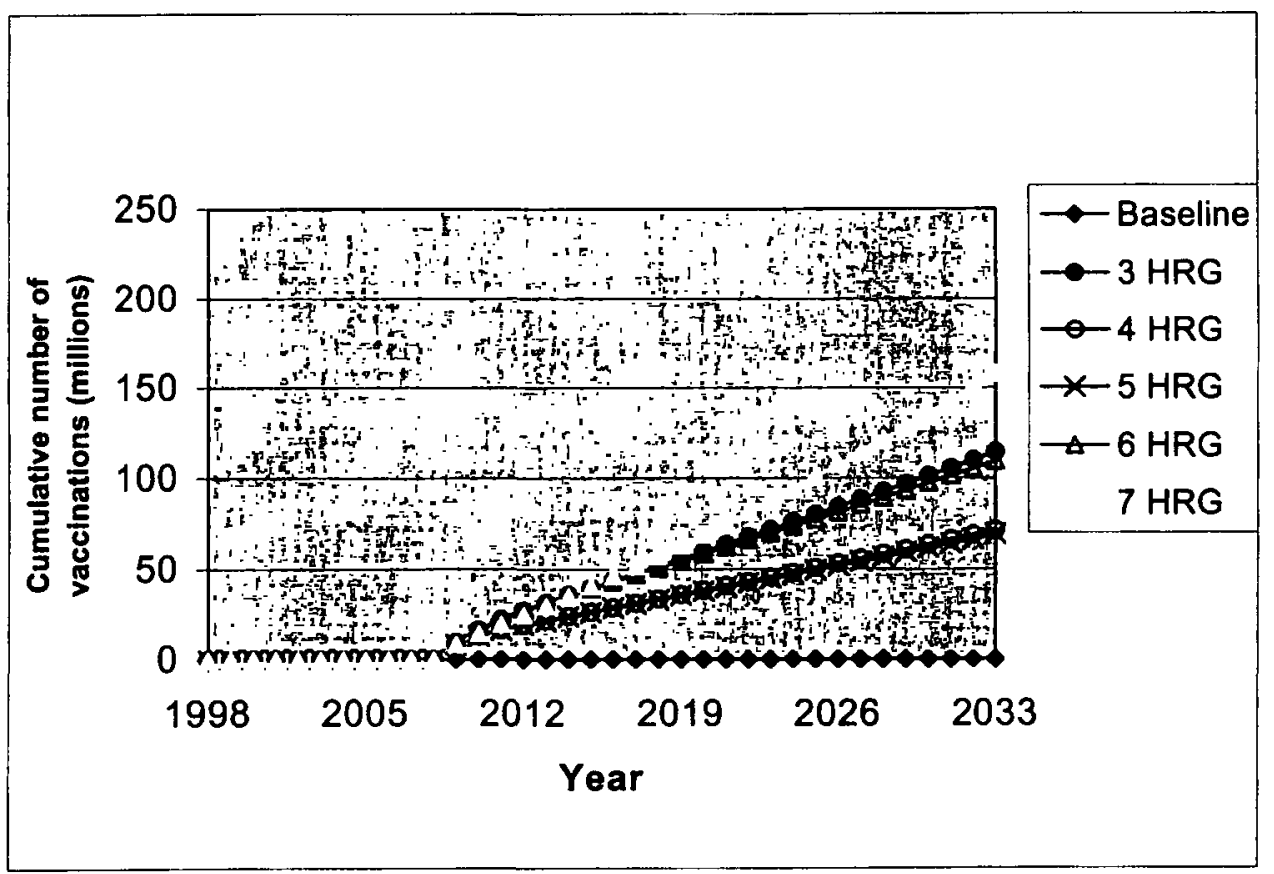


Table 3. Annual number of vaccinations (millions), by vaccination scenario

\begin{tabular}{|c|c|c|c|c|c|c|c|c|c|c|}
\hline Year & 3 Pop & 4Pop & SPop & $6 P o p$ & 7Pop & $3 H R G$ & $4 H R G$ & $5 H R G$ & $6 H R G$ & 7HRG \\
\hline 2008 & 0 & 0 & 0 & 0 & 0 & 0 & 0 & 0 & 0 & 0 \\
\hline 2009 & 36.75584 & 34.83045 & 34.83009 & 36.75562 & 35.24657 & 9.458652 & 8.191432 & 8.190107 & 9.4577 & 8.463783 \\
\hline 2010 & 32.95754 & 28.07567 & 28.07135 & 32.95466 & 30.39358 & 7.024372 & 4.732682 & 4.723124 & 7.015272 & 5.880448 \\
\hline 2011 & 6.244858 & 5.029587 & 5.026452 & 6.242568 & 6.04508 & 5.64389 & 3.323605 & 3.303129 & 5.61899 & 5.199646 \\
\hline 2012 & 6.2351 & 4.984517 & 4.977201 & 6.229522 & 6.485979 & 4.86343 & 2.748514 & 2.718075 & 4.819448 & 5.084898 \\
\hline 2013 & 6.231736 & 4.949949 & 4.936769 & 6.221292 & 6.808229 & 4.42484 & 2.514796 & 2.475336 & 4.3611 & 5.139177 \\
\hline 2014 & 6.234492 & 4.924991 & 4.904447 & 6.217654 & 7.051646 & 4.181922 & 2.421921 & 2.374015 & 4.09868 & 5.24384 \\
\hline 015 & 6.243104 & 4.908842 & 4.879604 & 6.218406 & 7.242737 & 4.051666 & 2.387704 & 2.331829 & 3.949434 & 5.36314 \\
\hline 016 & & 4.900801 & & & & & & & & \\
\hline 2017 & 6.276922 & 4.900245 & 4.850188 & 6.232322 & 7.53268 & 3.96011 & 2.379766 & 2.309487 & 3.821432 & 5.609946 \\
\hline 2018 & 30168 & 4.906626 & 4.8 & 6.245144 & 7.651148 & 3.95619 & 2.386378 & & 3.8 & 5.733307 \\
\hline 2019 & 6.331402 & 4.919453 & 4.844703 & 6.261668 & 7.7598 & 3.966054 & 2.395833 & 2.312953 & 3.792784 & 183 \\
\hline 2020 & .3659 & 4.938289 & 4.849935 & 6.281744 & 7.862127 & 3.984578 & 2.407233 & 2.318507 & 3.794608 & 5.978658 \\
\hline 2021 & & & & & & & 2.42026 & & & 907 \\
\hline 2022 & 6.448568 & 4.992467 & 4.874671 & 6.33202 & 8.056381 & 4.037122 & 2.434 & & 542 & 6.223 \\
\hline 2023 & 6.496434 & 5.027143 & 4.893588 & 6.36197 & 8.150922 & 4.068544 & 2.450875 & 2.345216 & 3.830102 & 6.345532 \\
\hline 2024 & 6.548474 & 5.066488 & 4.916528 & 6.394974 & 8.244798 & 4.10257 & 2.468455 & 2.3 & 3.84 & $6.4 c$ \\
\hline 2025 & 6.604564 & 5.110247 & 4.94326 & 6.430926 & 8.338489 & 4.138926 & 2.487564 & 2.370379 & 3.868744 & 6.591671 \\
\hline 2026 & 6.66459 & 5.158189 & 4.973572 & 6.469724 & 8.432323 & 4.177472 & 2.508202 & 2.385034 & 3.8 & 6.715784 \\
\hline 2027 & 6.728448 & 5.210106 & 5.007272 & 6.511276 & 8.526526 & 4.21814 & 2.530365 & 2.401028 & 3.915942 & 6.8 \\
\hline 2028 & 6.796044 & 5.265813 & 5.044189 & 6.555494 & 8.621255 & 4.260894 & 2.554045 & 2.418331 & 3.942418 & 6.966954 \\
\hline 2029 & 6.867288 & 5.325138 & 5.084162 & 6.602292 & 8.716624 & 4.30573 & 2.579222 & 2.436913 & 3.970718 & 7.094314 \\
\hline 2030 & 6.942102 & 5.387928 & 5.127048 & 6.6516 & 8.812714 & 4.352646 & 2.605879 & 2.456742 & 4.000782 & 7.223042 \\
\hline 2031 & 7.02041 & 5.454048 & 5.172717 & 6.703342 & 8.909587 & 4.401634 & 2.633994 & 2.477794 & 4.032574 & 7.353264 \\
\hline 2032 & 7.102148 & 5.523376 & 5.221045 & 6.75745 & 9.007293 & 4.4527 & 2.66354 & 2.500041 & 4.066054 & 7.485094 \\
\hline 2033 & 7.18726 & 5.595799 & 5.271928 & 6.813868 & 9.105866 & 4.505834 & 2.694497 & 2.523456 & 4.101184 & 7.618637 \\
\hline
\end{tabular}

\section{Discussion}

The HIV/AIDS epidemic in Southern India is more serious than that in most other parts of India. Current adult HIV prevalence approximates 2 percent, and in the absence of any intervention our model predicts a 7.5 percent adult HIV seroprevalence in 2033. Unfortunately, this prediction cannot be very precise as many model parameters are only approximately known.

Our model suggests that all interventions considered are potentially able to substantially dent the HIV epidemic. The effect of both highly effective vaccines and of a focused CSW intervention, based on condom promotion in which unprotected sex is reduced by 50 percent, is impressive. In the presence of a CSW intervention, prevalence would decline to 1.4 percent by 2033 , less than the prevalence in 2001 . This is consistent with the finding (Gangakhedkar and others, 1997) that infections among monogamous women in Pune (Maharashtra state) arise mostly from their husband's unprotected contact with sex workers. Even in mature epidemics, sex work is a key source of new infections. For example, adult prevalence in Cotonou, Benin, has exceeded 3 percent for the last decade or more. Careful work by Lowndes and others (2002) has concluded that virtually all of the ongoing HIV-1 transmission is related to 
infection of female sex workers, male clients of female sex workers, and the other nonregular sexual partners of those men.

Syndromic treatment of STIs would reduce HIV prevalence to 2.4 percent by 2033-not as impressive as a CSW intervention, but still important. It needs to be stressed however, that the empirical basis for the impact of syndromic treatment of STIs in India is less solid or well understood than that for focused CSW interventions, especially since preliminary results from the trial in Masaka, Uganda, have come out.

Preventive HIV vaccines could be highly effective in controlling the epidemic. Early understanding of the immunology correlates of HIV-1 protection, and the genetic variability and rapid mutations of the HIV virus all suggest that a high efficacy vaccine is unlikely at the outset, but could develop with continuous testing (Esparza 2001, Plummer and others 2001). A vaccine that conveys substantially less than full protection to those who are immunized will not prevent sex workers from getting infected, but would delay infection. Thus, targeting vaccines with low protection to high-risk groups is less effective than providing them with highly effective vaccines or condom-based programs. Moreover, sustained condom use among high-risk groups reduces transmission of STIs other than HIV.

Given a specified average vaccine efficacy, vaccines would be most effective if providing near 100 percent protection in to those who are immunized, even if not everyone vaccinated has an immunological response-in the terminology of Stover and others (2002), "take"-type efficacy. Vaccines that confer the same average partial level of protection to all vaccine recipients ("degree"-type efficacy) have less of an epidemiological impact. This makes sense, as partial protection may be insufficient to protect individuals with high-risk behaviors, although it would delay their infection. This is consistent with findings by Stover and others (2002).

A vaccine that confers 100 percent protection in 95 percent of all vaccine recipients could almost eradicate HIV within 25 years. Irrespective of the targeting strategy (the general population or high-risk groups), adult HIV prevalence would shrink to a mere 0.6 percent in 2033 and would subsequently decline even further. More importantly, this vaccine would still have a substantial impact, even if CSWclient condom use were to drop to zero (disinhibition). If high-risk populations were targeted with this highly effective vaccine and condom use were to drop, adult HIV prevalence in 2033 would be 1.4 percent; if the general population were targeted with this vaccine and with disinhibition, HIV prevalence would reach 2.1 percent.

The vaccine that would have the least effect is the vaccine that confers 50 percent protection to 50 percent of recipients-an average efficacy of only 25 percent. Adult HIV prevalence would rise to 3.7 percent in 2033 if high risk groups are targeted, while it would rise to 4.6 percent if the general population is targeted. The effects of this vaccine could be reversed by disinhibition, with adult HIV prevalence in 2033 of 10.3 percent (if high-risk groups are targeted) and 10.0 percent (population targeting), respectively. In other words, in the presence of disinhibition, HIV prevalence in 2033 
would be 2.5-2.8 percentage points higher than the projected baseline, which reaches 7.5 percent in that time frame. This is also broadly consistent with findings by Stover and others: "a vaccine with low efficacy and low duration could have negative impact on public health if its implementation were accompanied by widespread reversion to riskier sexual behaviors" (p. 29). They conclude that "with low efficacy vaccines it will be very important to support the vaccination program with efforts to combat any reversal to riskier sex. If efforts to maintain safer sex behaviors are not successful, then behavioral reversals could eliminate most of the benefits of the vaccine. In some cases the effect could be to increase HIV incidence" (p. 29).

Whether disinhibition is a likely scenario is unknown. It seems to be largely based on the experience with anti-retroviral therapy. While a vaccine may have the same effect, a vaccination campaign may also raise HIV awareness in the population and increase a sense of vulnerability in unvaccinated individuals. A sense of invulnerability in vaccinated individuals would only be a problem in partially effective vaccines.

Aside from effectiveness, there is the issue of the cost and feasibility of interventions. Interventions share infrastructure costs (e.g., surveillance costs would be used for both types of program). Large population laboratories are needed to support new generations of vaccine testing and newer intervention research on interventions for high-risk groups. These costs are often of the nature of joint costs. Costs for preventing HIV growth have to be integrated with costs of other interventions. For example, outreach campaigns for vaccines would probably aim to deliver several vaccines, including those for childhood vaccine preventable diseases.

The assumed vaccination coverage rates, while not 100 percent, even if integrated in existing structures, would still require substantial efforts and costs, with tens to hundreds of millions of vaccines administered over a 25-year period. A major advantage of a preventive HIV vaccine, which it shares with CSW and STI interventions, is that a potential recipient is not required to take an HIV test as a prerequisite for receiving a vaccine. While vaccines given to HIV-positive adults are clearly wasted (in the case of high-risk-group targeting this can be substantial), a policy of non-testing may be more efficient than one in which individuals are tested and counseled. Nevertheless, our estimates of the required number of vaccines only include vaccines for those who are HIV-negative. For population targeting, the wastage of vaccinating everybody is small. For high-risk populations, with a higher HIV prevalence, the wastage may be more substantial, at least in relative terms. Targeting high-risk groups is much more cost-effective than targeting the entire adult population. Using approximately one third of the number of vaccines, a higher reduction in prevalence is achieved. Although we did not explore this scenario, highly effective vaccines could be targeted to CSW only (i.e., excluding their clients), as in the long run this would be almost as effective as protecting both CSW and their clients. Vaccinating both CSWs and their clients would in the long run lead to substantial redundancy in 
prevention efforts. By contrast, for vaccines conferring partial protection or with a low "take" rate it would seem sensible to vaccinate both CSWs and their clients.

Conventional HIV prevention programs, especially those targeting CSWs (focused interventions) and using existing low-tech methods, may achieve results that are similar to reasonably effective vaccines and are probably less sensitive to disinhibition effects. It would therefore seem wise not to wait for the arrival of a vaccine, but to implement and expand focused CSW prevention programs as early and vigorously as possible. This will also create the infrastructure for effectively introducing HIV vaccines into these groups as soon as vaccines become available, and for scaling up vaccination campaigns. Such programs, however, require the political will to initiate and sustain them. Political support for vaccination campaigns, even for partially effective vaccines, may come easy, perhaps more so than for programs seemingly focusing on marginal groups such as CSWs. In sum, for the next few years expanding coverage of vulnerable group interventions while accelerating vaccine research and strengthening capacity for both with surveillance, human resource development, and operations research are the best strategies to contain the Indian HIV1 epidemic. When vaccines become available and particularly if efficacy or coverage is not perfect (most likely they are not!), then "other prevention programs should continue in conjunction with vaccination programs in order to reduce HIV infections to the lowest possible levels and maintain the other health benefits, such as prevention of sexually transmitted diseases" (Stover and others 2002, p. 30).

\section{References}

AP Benson, Inc. 1993-97. ModelMaker, version 3.0.3. United Kingdom: Old Beaconsfield, Buckinghamshire. [Website: http://www.modelkinetix.com/modelmaker/index.htm.]

Bhave, G., C.P. Lindan, E.S. Hudes, S. Desai, U. Wagle, S.P. Tripathi, and J. S. Mandel. 1995. "Impact of an intervention on HIV, sexually transmitted diseases, and condom use among CSW in Bombay, India." AIDS 9 Suppl 1: S21-30.

Esparza, J. 2001. "An HIV vaccine: how and when?" Bulletin of the World Health Organization 79: 1133-37.

Government of India (GOI), Office of the Registrar General and Census Commissioner. 2002. Census of India website. (Website: http://www.censusindia.net).

Gangakhedkar, R.R., M.E. Bentley, A.D. Divekar, D. Gadkari, S.M. Mehendale, M.E. Shepherd, R.C. Bollinger, and T.C. Quinn. 1997. "Spread of HIV infection in married monogamous women in India." Journal of the American Medical Association 278(23): 2090-92.

Gilson, L., R. Mkanje, H. Grosskurth, F. Mosha, J. Picard, A. Gavyole, J. Todd, P. Mayaud, R. Swai, L. Fransen, D. Mabey, A. Mills, and R. Hayes. 1997. "Cost-effectiveness of improved treatment services for sexually transmitted diseases in preventing HIV-1 infection in Mwanza Region, Tanzania." Lancet 350(9094): 1805-09.

Gray, R.H., M.J. Wawer, N.K. Sewankambo, D. Serwadda, C. Li, L.H. Moulton, T. Lutalo, F. Wabwire-Mangen, M.P. Meehan, S. Ahmed, L.A. Paxton, N. Kiwanuka, F. Nalugoda, E.L. Korenromp, and T.C. Quinn . 1999. "Relative risks and population attributable fraction of incident HIV associated with symptoms of sexually transmitted diseases and treatable symptomatic sexually transmitted diseases in Rakai District, Uganda." AIDS 13: 2113-23. 
Grosskurth, H., F. Mosha, J. Todd, E. Mwijarubi, A. Klokke, K. Senkoro, P. Mayaud, J. Changalucha, A. Nicoll, G. ka-Gina, et al. 1995. "Impact of improved treatment of sexually transmitted diseases on HIV infection in rural Tanzania: a randomised controlled trial." Lancet 346(8974): 530-36.

Hethcote, H.W., and J.A.Yorke. 1984. Gonorrhea transmission dynamics and control. Berlin: Springer Lecture Notes in Biomathematics 56.

Hitchcock, P., and L. Fransen. 1999. "Preventing HIV infection: lessons from Mwanza and Rakai." Lancet 353: 513-15

Hudson, C.P. 2001. "Community-based trials of sexually transmitted disease treatment: repercussions for epidemiology and disease prevention." Bulletin of the World Health Organization 79: 48-60.

Jana, S., N. Bandyopadhyay, S. Mukherjee, N. Dutta, I. Basu, and A. Saha. 1998. "STD/HIV Intervention with Sex Workers in West Bengal, India." AIDS 12 Suppl B: S101-S108.

Jana, S., and S. Singh. 1995. "Beyond the medical model of STD intervention--lessons from Sonagachi." Indian Journal of Public Health 39(3): 125-31.

Jha, P., N.J. Nagelkerke, E.N. Ngugi, J.V. Prasasa Rao, B. Willbond, S. Moses, and F.A. Plummer. 2001. "Reducing HIV transmission in developing countries." Science 292: 22425.

Katz, M.H., S.K. Schwarcz, T.A. Kellogg, J.D. Klausner, J.W. Dilley, S. Gibson, and W. McFarland. 2002. "Impact of highly active antiretroviral treatment on HIV seroincidence among men who have sex with men: San Francisco." American Journal of Public Health 92(3): 388-94.

Korenromp, E.L., S.J. de Vlas, N.J. Nagelkerke, and J.D. Habbema. 2001. "Estimating the magnitude of STD cofactor effects on HIV transmission- how well can it be done?" Sexually Transmitted Diseases 28(11): 613-21.

Korenromp, E.L., C. Van Vliet, H. Grosskurth, A. Gavyole, C.P. Van der Ploeg, L. Fransen, R.J. Hayes, and J.D. Habbema. 2000. "Model-based evaluation of single-round mass treatment of sexually transmitted diseases for HIV control in a rural African population." AIDS 14: 573-93

Kvale, G. 1999. "Preventing HIV-1: lessons from Mwanza and Rakai." Lancet 353: 1522-24.

Lowndes, C.M., M. Alary, H. Meda, C.A. Gnintoungbe, L. Mukenge-Tshibaka, C. Adjovi, A. Buve, L. Morison, M. Laourou, L. Kanhonou, and S. Anagonou. 2002. "Role of core and bridging groups in the transmission dynamics of HIV and STIs in Cotonou, Benin, West Africa." Sexually Transmitted Infection 78 Suppl 1: i69-77.

Matthys, F., and M. Boelaert. 1999. "Preventing HIV-1: lessons from Mwanza and Rakai." Lancet 353: 1523-24.

Moses, S., F.A. Plummer, E.N. Ngugi, N.J. Nagelkerke, A.O. Anzala, and J.O. Ndinya-Achola. 1991. "Controlling HIV in Africa: effectiveness and cost of an intervention in a high-frequency STD transmitter core group." AIDS 5: 407-11.

Nagelkerke, N.J., P. Jha, S.J. de Vlas, E.L. Korenromp, S. Moses, J.F. Blanchard, and F.A. Plummer. 2002. "Modelling HIV/AIDS epidemics in Botswana and India: impact of interventions to prevent transmission." Bulletin of the World Health Organization 80(2): 89-96.

Nagelkerke, N.J., P. Jha, S. de Vlas, E. Korenromp, S. Moses, J. Blanchard, and F. Plummer. 2001. "Modeling the HIV/AIDS epidemic in India and Botswana: the effects of interventions" (Internet communication, 23 November 2001, at http://www.cmhealth.org/docs/wg5 paper4.pdf.)

National AIDS Control Organisation (NACO). 2002. Website: http://naco.nic.in

National AIDS Control Organisation (NACO). 2002. National Baseline General Population Behavioural Surveillance Survey Report, 2001. Delhi: Ministry of Health and Family Welfare, Government of India. 
National Intelligence Council. 2002. "The Next Wave of HIV/AIDS: Nigeria, Ethiopia, Russia, India, and China." ICA 2002-04D, September. http://www.fas.org/irp/nic/hiv-aids.html

Nicoll, A., A.M. Johnson, M.W. Adler, and M. Laga. 1999. "Preventing HIV-1: lessons from Mwanza and Rakai." Lancet 353: 1522.

Ostrow, D.E., K.J. Fox, J.S. Chmiel, A. Silvestre, B.R. Visscher, P.A. Vanable, L.P. Jacobson, and S.A. Strathdee. 2002. "Attitudes towards highly active antiretroviral therapy are associated with sexual risk taking among HIV-infected and uninfected homosexual men." AIDS 16(5): 775-80.

Pais, P. 1996. "HIV and India: looking into the abyss." Tropical Medicine and International Health 1(3): 295-304.

Plummer, F.A., N. Nagelkerke, J.V.R. Prasada Rao, B. Willbond, E. Ngugi, S. Moses, G. John, R. Nduati, K.S. MacDonald, and S. Berkley. 2001. "The evidence base for interventions to prevent HIV infection in low and middle-income countries." Commission on Macroeconomics and Health Working Paper Series, no. WG5-2. August. [Retrieved on December 23, 2002 from http://www.cmhealth.org/docs/wg5 paper2.pdf.]

Rodrigues, J.J., S.M. Mehendale, M.E. Shepherd, A.D. Divekar, R.R. Gangakhedkar, T.C. Quinn, R.S. Paranjape, A.R. Risbud, R.S. Brookmeyer, D.A. Gadkari, et al. 1995. "Risk factors for HIV infection in people attending clinics for sexually transmitted diseases in India." British Medical Journal 311(7000): 283-86.

Stolte, I.G., N.H. Dukers, J.B. de Wit, J.S. Fennema, and R.A. Coutinho. 2001. "Increase in sexually transmitted infections among homosexual men in Amsterdam in relation to HAART." Sexually Transmitted Infection 77(3): 184-86.

Stolte, I.G., and R.A. Coutinho. 2002. "Risk behaviour and sexually transmitted diseases are on the rise in gay men, but what is happening with HIV?" Current Opinion in Infectious Diseases 15(1): 37-41.

Stover, J., G. Garnett, S. Seitz, and S. Forsythe. 2002. "The epidemiological impact of an HIV/AIDS vaccine in developing countries." World Bank Policy Research Discussion Paper, no. 2811. Development Research Department, World Bank, Washington, D.C. March. http://www.econ.worldbank.org/files/13172 wps2811.pdf

Venkataramana, C.B., and P.V. Sarada. 2001. "Extent and speed of spread of HIV infection in India through the commercial sex networks: a perspective." Tropical Medicine and International Health 6(12): 1040-61.

World Bank. 1997. Confronting AIDS: Public priorities in a global epidemic. Washington, D.C.: The World Bank. 
Annex 1. Description of the model, including a graphical representation.

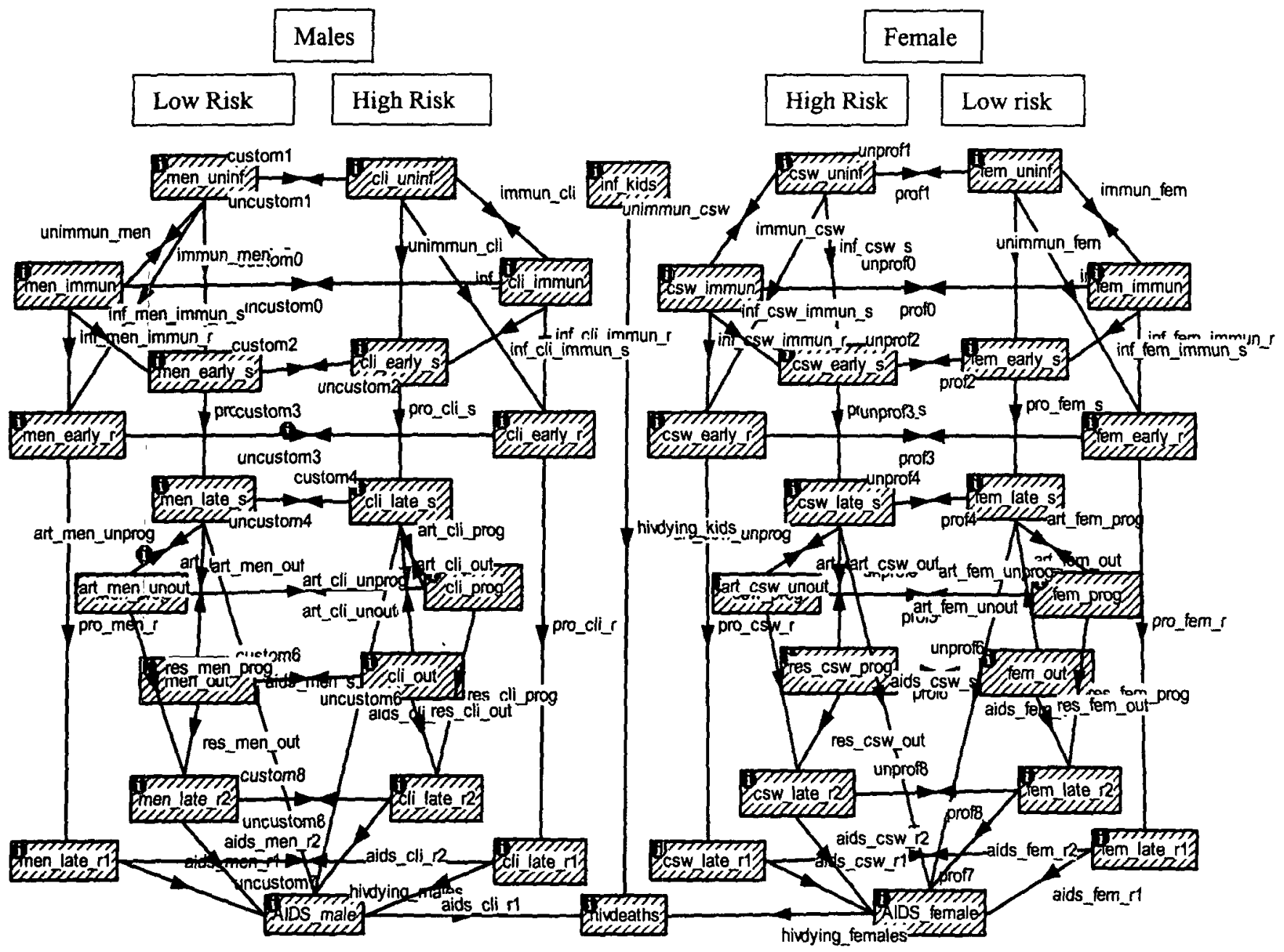




\section{COMPARTMENTS Differential equations and initial values}

\author{
AIDS_female \\ dAID $\bar{S}$ female/dt $=$ \\ taids_csw_staids_csw_rl+aids_fem_rl+aids_fem_s- \\ hivdying fermales- \\ mupos*AIDS femaletaids csw r2+alds fem $r 2$ \\ Initial Value $=0.0$
}

AIDS male

dAIDS male/dt = .

hivdying_malestaids_cli_rl+aids_men_rl+aids_men_stai ds cli_s-mupos*AIDS male+aids_men_r2+aids_cli_r2

Initial Value $=0.0$

cli_early_r

dcli_early_t/dt = -mupos*cli_early_r+custom3uncustom $3+$ inf_cli_r-pro_cli_rtinf_cli_immun_r Initial Value $=\overline{0} .0$

cli_early_s

dcli early $s / d t=-$ mupos*cli_early_s+custom2uncustom2+inf_cli_s-pro_cli_stinf_cli_immun_s Initial Value $=$ init_pop_male ${ }^{*}$ init_frac_cli*init_inf_cli* $(1$ hivprog/(aidsrate+hivprog)* hivprog/(hivprog+uncust))

cli_immun

$\mathrm{dcli}$ immun/dt $=-$ muneg ${ }^{*} \mathrm{cli}$ immuntcustom0-

uncustom0+immun_cli-inf_cli_immun_r-ınf_cli_immun_sunimmun_cli

Initial Value $=0.0$

\section{cli_late_r1}

dcli late $\mathrm{rl} / \mathrm{dt}=-$ mupos* ${ }^{*} \mathrm{cli}$ late $\mathrm{rl}+$ custom 7 -

uncustom7+pro_cli_r-aids_cli_rl

Initial Value $=0.0$

cli late $r 2$

dcli_late_ $\mathrm{r} 2 / \mathrm{dt}=-$ mupos ${ }^{*}$ cli_late_r2+custom8uncustom8+res_clı_prog+res_cli_out-aids_cli_r2 Initial Value $=\overline{0} .0$

cil_late_s

dcli_late_s $/ \mathrm{dt}=$-mupos*cli_late_stcustom4uncustom4+pro_cli_s-art_cli_progtart_cli_unprogart cli out+art_cli_unout-aids_cliss

Initial Value $=$

init_pop_male*init_frac_cli*init_inf_cli*hivprog/(aidsrate+ hivprog)*hivprog/(hivprog+uncust)

cli out

dcli out/dt $=$-mupos*cli_out+custom6-

uncustom6+art_cli_out-art_cli_unout-res_cli_out

Initial Value $=\overrightarrow{0} .0$

cll_prog

$\mathrm{dcli}$ prog/dt $=$-mupos*cli progtcustom5-

uncustom5+art_cli_prog-art_cli_unprog-res_cli_prog

Initial Value $=\overline{0} .0$

cli uninf

$\mathrm{dcli}$ _uninf/dt $=-$ muneg*cli_uninf + custom 1 -uncustom 1 -

inf cli r-inf cli s-immun clitunimmun cli

Initial Value $=$ init_pop_male*init_frac_cli* $(1-i n t$ _inf_cl $)$

csw_early_r

dcsw_early_r $r / d t=-$ mupos* ${ }^{*} \operatorname{csw}$ _early_rtprof3-

unprof $3+$ inf_csw_r-pro_csw_r+inf_csw_immun_r

Initial Value $=0.0$ csw_early_s

dcsw_early_s $/ \mathrm{dt}=-$ mupos*csw_early_stprof2-

unprof2+inf_csw_s-pro_csw_stinf_csw_immun_s

Initial Value $=$

init pop female ${ }^{*}$ init frac csw*init inf $\operatorname{csw}^{*}(1$ -

hivprog/(ardsrate+hivprog) ${ }^{*}$ hivprog/(hivprog+unprof))

csw_immun

$\mathrm{dcsw}$ immun $/ \mathrm{dt}=-$ muneg ${ }^{*} \mathrm{csw}$ Immun-

unprof $0+$ prof $0+1 m m u n$ csw-inf $\overrightarrow{c s w}$ immun $r$ -

inf csw immun s-unimmun_csw

Initial Value $=0.0$

csw late $\mathbf{r} 1$

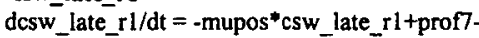

unprof $7+$ pro csw_r-aids_csw $\overline{\mathrm{rl}}$

Initial Value $=0.0$

csw late $r_{2}$

dcsw_late_r2/dt $=-$ mupos*csw_late_r2+prof8-

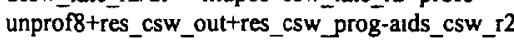

Initual Value $=0 . \overline{0}$

csw late $s$

desw late $s / d t=-$ mupos $*$ csw late stprof4-

unprof4+pro_csw_s-art_csw_progtart_csw_unprog-

art_csw_out +art_csw_unout-atds_csw_s

Initial Value $=$

init_pop_female*init_frac_csw*intt_inf_csw*hivprog/(aids rate+hivprog)*hivprog/(hivprog+unprof)

csw out

desw_out $/ \mathrm{dt}=-$ mupos* ${ }^{*} \mathrm{csw}$ out + prof6-

unprof6+art_csw_out-art_csw_unout-res_csw_out

Initial Value $=0 . \overline{0}$

\section{csw prog}

dcsw_prog/dt $=-$ mupos* ${ }^{*} \operatorname{csw}$ prog+prof5

unprofstart_csw_prog-art_csw_unprog-res_csw_prog

Initial Value $=0.0$

csw_uninf

dcsw unınf/dt $=$-muneg ${ }^{*}$ csw uninftprofl-unprofl -

inf_csw_r-inf_csw_s-immun_csw+unimmun_csw

Initial Value $=$ init pop female*init frac $\operatorname{csw}^{*}(1-$

init_inf_csw)

cum_incidence

dcum incidence $/ \mathrm{dt}=$ incidence

Initial Value $=0.0$

fem_early_r

dfem_early_r $r d t=-$ mupos*fem_early_r

prof $3+$ unprof $3+$ inf fem_r-pro_fem_r+inf fem immun $r$

Initial Value $=0.0$

fem_earlys

dfem_early_s/dt $=$-mupos*fem_early_s-

prof $2+$-unprof $2+$ inf_fem_s-pro_fem_stinf_fem_immun_s

Initıal Value $=$ init_pop_female* $(1$ -

init_frac_csw)*init_inf_fem*aidsrate/(aidsrate+hivprog)

fem immun

dfem immun $/ \mathrm{dt}=-$ muneg ${ }^{*}$ fem immuntunprofo-

profo+immun_fern-inf_fem_immun_r-inf_fem_immun_s-

unımmun fem

Initial Value $=0.0$

fem_late_rl

dfem_late_rl $1 / \mathrm{dt}=-$ mupos*fern_late_rl-

prof $7+$ unprof $7+$ pro fem r-aids fem $r l$

Initial Value $=0.0$

fem_late $\mathbf{r}^{2}$ 
dfem late $r 2 / d t=-$ mupos*fem late $r 2$ -

prof8+unprof8+res_fem_prog+res_fem_out-aids_fem_r2 Initial Value $=0.0$

fem_late_s

dfem_late_s $/ \mathrm{dt}=-$ mupos ${ }^{*}$ fem late $s$ -

prof4+unprof4+pro fem s-art fem progtart fem unprog-

art_fem_out+art_fem_unout-aids_fem_s

Initial Value $=$ init pop female* $\overline{(1}$ -

init frac_csw)*init inf fem ${ }^{*}$ hivprog/(aidsrate+hivprog)

fem_out

dfem out/dt = -mupos*fem out

prof6+unprof6+art_fem_out-art_fem_unout-res_fem_out Initial Value $=0.0$

\section{fem_prog}

dfem prog/dt = -mupos*fem prog-

profs+unprofs+art fem prog-art fem unprog-

res_fem_prog

Initial Value $=0.0$

fem_uninf

dfem uninf/dt $=-$ muneg*fem uninf-profl +unprofl-

inf fem r-inf fem stpopulation * femgr-

immun_femtunimmun_fem

Initial $\bar{V}$ alue $=$ init pop female* $(1 \text {-init frac csw })^{*}(1$

init_inf_fem)

\section{hivdeaths}

dhivdeaths $/ \mathrm{dt}=$

thivdying_malesthivdying_femalesthivdying_kids

Initial Value $=0.0$

Inf_kids

$\operatorname{dinf}$ kids/dt $=$ +inf births-hivdying kids

Initial Value $=0.0$

men_early_r

dmen_early_t $t \mathrm{dt}=-$ mupos*men_early_r

custom $3+$ uncustom $3+i n f$ men_r-

pro men $r+i n f$ men immun $r$

Initial Value $=\overline{0} .0$

men_early_s

dmen_early_s $/ \mathrm{dt}=-$ mupos*men_early_s-

custom 2 + uncustom $2+$ inf_men_s-

pro men stinf men immun $s$

Initial Value $=$ init_pop_male ${ }^{*}(1-$

init_frac_clı)*init_inf_men*aidsrate/(aidsrate+hivprog)

men immun

dmen_immun $/ \mathrm{dt}=-$ muneg ${ }^{*}$ men_immun-

custom0+uncustom0+immun men-inf men immun r-

inf_men_immun_s-unimmun_men

Initial Value $=0 . \overrightarrow{0}$

men late $r 1$

dmen late $\mathrm{rl} / \mathrm{dt}=-$ mupos ${ }^{*}$ men late $\mathrm{rl}$ -

custom 7 +uncustom 7 +pro men $r$-aids men $r$

Initial Value $=0.0$

men late r2

dmen_late_r2/dt = -mupos*men_late_r2-

custom $8+$ uncustom8+res_men_out+res_men_prog-

aids men $r 2$

Initial Value $=0.0$

men_late_s

dmen_late_s/dt $=$-mupos*men_late_s-

custom $4+$ uncustom4 +pro men $s$ -

art men progtart men unprog-

art_men_out+art_men_unout-aids_men_s

Initial Value $=$ init pop male* $(1-$

init frac cli)*init inf men*hivprog/(aidsrate+hivprog) men_out

dmen_out/dt $=$-mupos*men_out-

custom6+uncustom6+art men out-art men unout-

res_men_out

Initial Value $=0.0$

men_prog

dmen prog/dt $=-$ mupos*men prog-

custom5+uncustom5+art men_prog-art men_unprog-

res_men_prog

Initial Value $=0.0$

men uninf

dmen_uninf $/ \mathrm{dt}=-$ muneg*men uninf-custom 1 +uncustoml-

inf men r-inf men stpopulation*malegr-

immun_mentunimmun_men

Initial Value $=$ init pop_male* $(1 \text {-init frac cli })^{*}(1$ -

init_inf_men)

prog_recr

dprog $\mathrm{recr} / \mathrm{dt}=$

art_men_prog+art_cli_prog+art_csw_prog+art_fem_prog

Initial Value $=0.0$

wild_recr

dwild $\mathrm{recr} / \mathrm{dt}=$

art men out+art cli out+art csw out+art fem out

Initial Value $=0.0$

\section{FLOWS}

\section{Movements between compartments}

aids_cli $r 1$

Flow from cli late $\mathrm{rl}$ to AIDS male

ands_cli_rl = aidsrate ${ }^{*}$ cli_late_rl

aids_cll_r2

Flow from cli late_ $r 2$ to AIDS_male

ards_cli $r 2=$ aidsrate $*$ cli late_r2

aids_cli_s

Flow from cli late $s$ to AIDS male

aids_cli_s $=$ aidsrate $*$ cli_late_s

aids_csw_r1

Flow from CSW_late_rl to AIDS_female

aids_csw_rl $=$ aidsrate $*$ csw_late_rl

aids_csw_r2

Flow from CSW_late_r2 to AIDS_female

aids_csw_r2 = aidsrate * csw late r2

aids_csw_s

Flow from CSW late $s$ to AIDS female

aids_csw_s $=$ aidsrate ${ }^{*} \mathrm{csw}$ late_s

aids_fem_r1

Flow from fem_late_rl to AIDS_female

aids_fem_rl $=$ aidsrate $*$ fem_late_rl

alds fem $r 2$

Flow from fem_late_r 2 to AIDS_female aids_fem $r 2=$ aidsrate * fem late $r 2$

aids_fem s

Flow from fem late $s$ to AIDS female

aids_fem_s $=$ aidsrate $*$ fem_late_s

aids_men_r1

Flow from men late rl to AIDS male

ards_men $\mathrm{rl}=\overline{\text { aidsrate }}$ * men late $\mathrm{rl}$

aids_men_r2 
Flow from men_late_r2 to AIDS_male aids_men_r2 = aidsrate * men_late_r2

aids_men_s

Flow from men_late_s to AIDS male aids_men_s $=$ aidsrate $*$ men_late_s

art_cli_out

Flow from cli late $s$ to cli out art_cli_out $=$ recr_cli_out ${ }^{*}$ cli_late_s

art cli prog

Flow from cli_late_s to cli prog

art cli prog $=$ recr_cli prog $*$ cli lates

art cll unout

Flow from clı out to cli lates

art_clı_unout $=$ outloss * cli_out

\section{art cli unprog}

Flow from clı prog to cli late

art_clı_unprog $=$ progloss ${ }^{*}$ cli.jprog

art_csw_out

Flow from csw_late_s to csw_out

art_csw_out $=$ recr_CSW_out $*$ csw_late_s

art_csw_prog

Flow from csw late $s$ to csw prog

art_csw_prog $=$ recr_csw_prog ${ }^{*} \mathrm{csw}$ late_s

\section{art csw unout}

Flow from CSW out to csw lates

art csw_unout $=$ outloss $*$ csw_out

\section{art_csw_unprog}

Flow from csw_prog to csw_late_s

art_csw_unprog $=$ progloss ${ }^{\overline{ }} \mathrm{csw}$ prog

art_fem_out

Flow from fem late s to fem_out art_fem_out $=$ recr_fem_out ${ }^{*}$ fem_late_s

art_fem_prog

Flow from fem_late_s to fem_prog

art_fem_prog $=$ recr_fem_prog * fem_late_s

art fem unout

Flow from fem_out to fem_late_s

art_fem_unout $=$ outloss $*$ fem_out

art_fem_unprog

Flow from fem prog to fem late $s$ art_fem_unprog $=$ progloss $*$ fem_prog

art men out

Flow from men_late_s to men_out art_men_out $=\overline{\text { recr_men_out }}{ }^{-}$men_late_s

art_men_prog

Flow from men late $s$ to men prog

art_men_prog $=$ recr_men_prog * men_late_s

art_men_unout

Flow from men_out to men_late_s

art_men_unout $=$ outloss $*$ men_out

art_men_unprog

Flow from men_prog to men_late_s

art_men_unprog $=$ progloss * men_prog

custom0

Flow from men immun to cli immun

custom $0=$ cust ${ }^{-}$men_immun custom1

Flow from men_uninf to cli_uninf

customl $=$ cust $^{*}$ men_uninf

custom2

Flow from men early s to cli_early_s custom2 $=$ cust ${ }^{*}$ men_early_s

custom3

Flow from men_early_r to cli_early_ $r$ custom $3=$ cust ${ }^{*}$ men_early_ $\vec{r}$

custom4

Flow from men_late_s to cli_late s

custom $4=$ cust ${ }^{*}$ men_late_s

custom5

Flow from men prog to cli prog

custom5 = cust * men_prog

custom6

Flow from men_out to cli_out

custom $6=$ cust ${ }^{*}$ men_out

custom7

Flow from men late $r$ l to cli late_ $r l$

custom7 = cust ${ }^{*}$ men_late_r 1

custom8

Flow from men_late_r2 to cli_late_r2

custom $8=$ cust ${ }^{*}$ men_late_r $\overline{2}$

hivdying females

Flow from AIDS_female to hivdeaths

hivdying_females $=$ round(muaids * AIDS_female)

hivdying kids

Flow from Inf kids to hivdeaths

hivdying_kids $=$ round(muhiv_kids * inf_kids)

hivdying males

Flow from AIDS_male to hivdeaths

hivdying_males = round(muaids* AIDS_male)

immun_cli

Flow from cli_uninf to cli_immun

immun_cl $1=$ vactake ${ }^{*}$ vacrate_cli*cli_uninf

immun_csw

Flow from csw uninf to csw immun

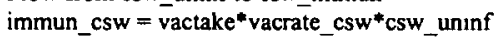

immun fem

Flow from fem_uninf to fem_immun

immun_fem $=$ vactake ${ }^{*}$ vacrate_fem ${ }^{*}$ fem_uninf

Immun_men

Flow from men_uninf to men_immun

immun_men $=$ vactake ${ }^{*}$ vacrate_men ${ }^{*}$ men_uninf

Inf cli immun $r$

Flow from cli_immun to cli_early_r

inf_cli_immun_ $r=$ vaceff* $\left(\right.$ cli_immun $^{*} \mathrm{cr}^{*}$ fmrisk ${ }^{*}$ unprot *

( $w 1^{*} \operatorname{csw}$ early $r+w 2 * \operatorname{csw}$ late $r 1+w 2 *$ counsel $c s w^{*}(1-$

sustrans) ${ }^{\bar{*}}$ csw_late_r2) / csw)

Inf_cli_immun_s

Flow from cli_immun to cli_early_s

inf_cli_immun_s $=$ vaceff* (cli_immun ${ }^{*} \mathrm{cr}^{*} \mathrm{fmrisk}^{*}$ unprot *

(w1*csw_early_s + w2*csw_late_s +

w2* counsel_csw*sustrans*csw_late_r2+

w2*resid_infect*csw_out) / csw)

inf_cli_r

Flow from cli_uninf to cli_early_r 
inf cli $r=$ STD control* ${ }^{*}$ cli uninf ${ }^{*} r^{*}$ fmrisk* unprot * $\left(w \bar{l}^{*} \mathrm{csw}\right.$ _early_$r+w 2 * \mathrm{csw}$ late_rl $+w 2 *$ counsel_csw*(1sustrans) $\left.{ }^{*} \operatorname{csw} \overline{l a t e}_{-}(2) / \mathrm{csw}\right)$

inf_cli_s

Flow from cli_uninf to cli_early_s

inf cli $s=S T D$ control ${ }^{*}$ (cli uninf* ${ }^{*}{ }^{*}$ fmrisk* unprot *

(wI*csw_early_s + w2*csw_late_s +

w2* counsel_csw* sustrans* ${ }^{*}{ }^{*} w$ late_r2 +

w2*resid_infect*csw_out) / csw)

Inf esw immun_

Flow from csw_immun to csw_early_t

inf $c s w$ immun_ $r=$ vaceff $^{*}\left(\mathrm{csw}_{-}\right.$immun

*annualCSWcontacts*mfrisk*unprot * (wl ${ }^{*}$ cli early $r+$ w2*cli_late_r1 +w2*counsel_cli*(1-sustrans)*cli_late_r2) / clients)

Inf_csw_immun_s

Flow from csw immun to csw_early_s

inf csw immun $s=$ vaceff*(csw immun

+annualCSWcontacts*mfrisk"unprot * (w1*cli early $s+$

w2*cli_late_s $+w 2 *$ counsel_cli*sustrans*cli_late_r $2+$

w2*resid infect* cli out) / clients)

inf_csw_r

Flow from csw_uninf to csw early

inf csw $r=$ STD_control* (csw_uninf

*annualCSW contacts ${ }^{*}$ mfrisk"unprot * (wl *cli_early_r +

$w 2 *$ cli_late_rl +w2*counsel_cli*(1-sustrans)*cli_late_r2) /

clients)

inf csw $s$

Flow from csw_uninf to csw_early_s

inf_csw_s = STD_contro)"(csw_uninf

*annualCSW contacts*mfrisk"unprot * (wl *cli early_s +

$w 2 *$ cli late $s+w 2 *$ counsel cli*sustrans*cli late $r 2+$

w2*resid_infect*cli_out)/clients)

Inf_fem_immun_r

Flow from fem_immun to fem_early $r$

inf fem immun $r=$ vaceff* (leak* (w1 *cli early $r+$

$\mathrm{w} 2$ cli_late_rl $+\mathrm{w} 2 *$ counsel_cli*(1-sustrans $) * \mathrm{cli}$ late $r 2+$

$w 1 *$ men_early_r $+w 2 *$ men_late_rl+w2*counsel_men $*(1$ -

sustrans)*men late $r 2$ ) * fem immun/fem +

fem immun*stabfactor"mfrisk*marrate2 *

$\left(w 1^{*}\right.$ men_early_r $+w 2 *$ men_late_rl+

w2* counsel men*(1-sustrans)*men late $r 2) /$ men $)$

inf fem immuns

Flow from fem immun to fem earlys

inf_fem_immun_s $=$ vaceff* $\left({ }_{\text {leak}} *\left(w^{*}{ }^{*}\right.\right.$ cli_early_s +

$w 2 * \mathrm{cli}$ late_s $+\mathrm{w} 2 *$ counsel_cli*sustrans*cli_late_r2 +

$w 2 *$ resid infect ${ }^{*}$ cli out $+w l^{*}$ men early s +

$w 2 *$ men_late_s $+w \overline{2} *$ coursel_men * sustrans*men_late_r2

$+w 2 *$ resid_infect*men_out) * fem_immun/fem

+fem immun *stabfactor*mfrisk*marrate2 *

(w1*men_early_s + w2*men_late_s +

w2*counsel_men*sustrans*men_late_r2 +

w2* resid infect*men out) / men )

inf_fem_r

Flow from fem uninf to fem early $r$

inf_fem_r $=$ STD_control*( $\left(\right.$ leak ${ }^{*}$ (wl* ${ }^{*}$ cli_early_r +

$w 2^{*}$ cli_late_rl + w2*counsel_cli*(1-sustrans)*cli_late_r2 + $w 1 *$ men early $\mathrm{r}+\mathrm{w} 2 *$ men late $\mathrm{rl}+\mathrm{w} 2 *$ counsel men $*(1-$ sustrans) ${ }^{*}$ men_late_r2) * fem_uninf/fem +

fem_uninf*stabfactor*mfrisk* marrate2 * (w1*men_early_t

$+w 2 *$ men late $r 1+w 2 *$ counsel men* $(1$ -

sustrans)*men_late_r2) (men))

inf fem s

Flow from fem_uninf to fem_early_s

inf fem_s $=$ STD_control $*\left(\right.$ lieak $^{*}\left(\right.$ w $1^{*}$ cli_early_s +

$w 2{ }^{*}$ cli_late_s $+w 2 *$ counsel_cli*sustrans ${ }^{*}$ cli_late_r2 + $w 2 *$ resid infect"cli out $+w 1 *$ men early $s+$

$w 2 *$ men_late_s $+w \overline{2}$ "counsel_men"sustrans"men_late_r2

$+w 2 *$ resid_infect*men_out) * fem_uninf/fem

+ fern uninf" stabfactor *mfrisk*marrate2 *

(w1*men early $s+w 2 *$ men late $s+$

w2*counsel_men*sustrans*men_late_r2 +

w2*resid_infect*men_out) / men ))

inf_men_Immun_r

Flow from men immun to men early $r$

inf_men_immun_ $r=$ vaceff $^{*}\left(\overline{l i l e a k}^{*}\left(\bar{w} l^{*} \mathrm{csw}{ }_{-}\right.\right.$early_ $r+$

$w 2 * c s w$ late_rl $r+w 2 *$ counsel_csw* $(1-$

sustrans) $)^{*} \mathrm{csw}$ late $\mathrm{r} 2+\mathrm{w} \mathrm{l}^{*}$ fem early $r+$

$w 2 *$ fem late $\bar{r} 1+\bar{w} 2 *$ counsel fem* $* 1$ -

sustrans) ${ }^{*}$ fem_late_r2) * men_immun/men+

men immun *stabfactor *fmrisk"marrate * (w1 *fem early $r$ $+w 2^{*}$ fem_late_r $r+w 2 *$ counsel_fem* $(1-$

sustrans)* ${ }^{*}$ fem_late_r2) / fem ))

inf_men_immun_s

Flow from men_immun to men_early_s

Inf men immun $s=$ vaceff* (leak ${ }^{*}\left(w 1^{*} \mathrm{csw}\right.$ early $s+$

$w 2 * \mathrm{csw}$ late_s $+\mathrm{w} 2 *$ counsel_csw*sustrans ${ }^{*} \mathrm{csw}$ _late_r $2+$

w2*resid_infect ${ }^{*} \mathrm{csw}$ out $+\mathrm{w}^{*}$ *fem_early_s +

$w 2 *$ fem late $s+w 2 *$ counsel fem ${ }^{*}$ sustrans ${ }^{*}$ fem late $\mathrm{r} 2+$

w2*resid_infect *fem_out) * men_immun/men+

men_immun *stabfactor* fmrisk*marrate *

(w1*fem early $s+w 2 *$ fem late $s$

$+w 2 *$ counsel_fem* sustrans* fem_late_r2+

w2* resid_infect*fem_out) / fem )

inf men $r$

Flow from men uninf to men early_t

inf men $r=S T D$ control* ( (leak" $(w)^{*} \operatorname{csw}$ early $r+$

$w 2 * \mathrm{csw}$ late_rl $+\mathrm{w} 22^{*}$ counsel_csw* $(1$ -

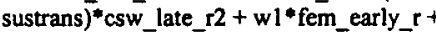

w2*fem late $r 1+{ }^{*} 2 *$ counsel fem* $(1$ -

sustrans)*fem_late_r2)*men_uninf/men+

men_uninf*stabfactor ${ }^{*}$ fmrisk ${ }^{*}$ marrate * (wl ${ }^{*}$ fem_early_r

$+w 2 *$ fem late $r l+w 2 *$ counsel fem $*(1$ -

sustrans)* $\overline{f e m}_{\text {late_r2) } / \text { fem )) }}$

inf_men_s

Flow from men_uninf to men_early_s

inf men $s=$ STD_control* ( (leak* $(w)^{*} \mathrm{csw}$ early $s+$

$w 2^{*} \mathrm{csw}$ late_s $+\overrightarrow{\mathrm{w}} 2$ "counsel_csw"sustrans ${ }^{*} \mathrm{csw}$ late_r2 +

w2"resid_infect"csw_out $+w 1$ *fem_early_s +

$w 2 *$ fem_late stw2* counsel_fem*sustrans*fem_late_r2 +

w2*resid_infect*fem_out) *men_uninf/ment

men_uninf*stabfactor ${ }^{*}$ fmrisk*marrate * (w1 *fem_early_s

$+w 2^{*}$ fem late $s+w 2$ "counsel fem "sustrans ${ }^{*}$ fem late $r 2$

+ w2*resid_infect*fem_out) / fem ))

pro cli $r$

Flow from cli_early_ $r$ to cli_late_ $r$ l

pro_cli_r $=$ hivprog cli_early_r

pro cli s

Flow from cli_early_s to cli_late_s

pro_cli_s $=$ HİVprog * cli_early_s

pro_esw_r

Flow from CSW early $r$ to CSW late $r l$

pro_csw_r $=$ hivprog $*$ csw_early_r

pro_csw_s

Flow from CSW_early_s to CSW_late_s

pro_csw_s $=H I \bar{V}$ prog ${ }^{*}$ csw_early_s

pro_fem_r

Flow from fem_early_r to fem_late_rl

pro fem $r=$ hivprog fem early $r$

pro_fem_s

Flow from fem early s to fem late $s$ 
pro_fem_s $=$ HIVprog $*$ fem_early_s

pro_men_r

Flow from men early $r$ to men late $r$

pro_men_ $r=$ hivprog ${ }^{*}$ men_early_ $r$

\section{pro men s}

Flow from men_early_s to men_late_s

pro_men_s $=$ HIVprog $*$ men_early_s

profo

Flow from fem immun to csw immun

profo $=$ prof* $\exp ($ annualCSWcontacts $/ 1000-1) *$

fem_immun

\section{prof}

Flow from fem_uninf to csw_uninf

prof1 $=$ prof* fem_uninf*exp(annualCSWcontacts/1000-1)

prop

Flow from fem_early_s to csw_early_s

prof2 $=$ prof* fem_early_s* exp(annualCSWcontacts $/ 1000$ 1)

\section{proß3}

Flow from fem_early_r to CSW early_r

prof3 $=$ prof * fem_early_r ${ }^{*} \exp ($ annualCSWcontacts $/ 1000$ 1)

\section{prof4}

Flow from fem_late_s to CSW_late_s

prof $4=$ prof* $\exp ($ annualCSWcontacts $/ 1000-1)$ *

fem_late_s

prot5

Flow from fem prog to CSW prog

prof $5=$ prof*exp(annualCSWcontacts $/ 1000-1) *$ fem_prog

prof6

Flow from fem_out to CSW_out

prof6 $=$ prof"exp(annualCSW $\bar{W}$ contacts/1000-1) * fem_out

prof7

Flow from fem_late_rl to CSW late_rl

prof7 = prof*exp(annualCSWcontacts/1000-1)*

fem_late_rl

prof8

Flow from fem_late_r2 to CSW_late_r2

prof8 $=$ prof*exp(annualCSWcontacts $/ 1000-1) *$

fem_late_r2

res_cli_out

Flow from cli out to cli late $r 2$

res_cli_out $=\overline{\text { outRDR }} * \overline{\text { cli_out }}$

res_cli_prog.

Flow from cli_prog to cli_late_r2

res_cli_prog $=$ progRDR * cli_prog

res_csw_out

Flow from csw_out to csw_late $r 2$

res_csw_out $=\overline{\text { outRDR }} * \overline{c s w}$ _out

res_csw_prog

Flow from csw_prog to csw_late_r2

res_csw_prog $=$ progRDR $*$ csw_prog

res_fem_out

Flow from fem_out to fem_late_r2

res_fem_out $=$ outRDR * fem_out

res_fem_prog

Flow from fem prog to fem late r2

res_fer_prog $=$ progRDR * fem_prog res_men_out

Flow from men_out to men_late_r2

res_men_out $=\overline{\text { outRDR }}$ * men_out

res_men_prog

Flow from men_prog to men_late_r2

res_men_prog $=$ progRDR $*$ men_prog

uncustom 0

Flow from cli_immun to men_immun

uncustom $0=$ uncust * cli_immun

uncustom 1

Flow from cli_uninf to men_uninf

uncustom 1 = uncust* cli_uninf

uncustom2

Flow from cli_early_s to men_early_s

uncustom2 = uncust ${ }^{*}$ cli_early_s

uncustom3

Flow from cli_early_r to men_early_r uncustom $3=$ uncust * cli_early_r

uncustom4

Flow from cli_late s to men_late $s$

uncustom4 $=$ uncust $*$ cli_late_s

uncustoms

Flow from cli_prog to men_prog

uncustoms = uncust * cli_prog

uncustom 6

Flow from cli_out to men_out

uncustom $6=$ uncust * cli_out

uncustom 7

Flow from cli_late_rl to men_late $r 1$

uncustom $7=\overline{\text { uncust }} *$ cli_late_rl

uncustom8

Flow from cli_late_r2 to men_late_r2

uncustom8 $=\overline{\text { uncust }}$ * cli_late_r2

unimmun cli

Flow from cli_ummun to cli uninf

unimmun_cli $=$ loss_1mmun ${ }^{*}$ cli_immun

unimmun csw

Flow from csw_immun to csw_uninf

unimmun_csw $=$ loss_immun ${ }^{*} \mathrm{csw}$ _immun

unimmun fem

Flow from fem_immun to fem_uninf

unimmun_fem $=$ loss_immun ${ }^{*}$ fem_immun

unimmun_men

Flow from men_tmmun to men uninf

unimmun_men $=$ loss_immun * men_immun

unproro

Flow from csw_immun to fem_immun

unprofo $=$ unprof * csw_immun

unprof

Flow from csw_uninf to fem_unınf

unprofl $=$ unprof* csw_uninf $\bar{f}$

unprop

Flow from CSW early s to fem early s

unprof2 $=$ unprof ${ }^{w}$ csw_early_s

unprof3

Flow from CSW_early_r to fem_early_r 
unprof3 $=$ unprof * csw_early_r

unprof4

Flow from CSW_late_s to fem_late_s

unprof $4=$ unprof ${ }^{*} \mathrm{csw}_{-}$late_s

unprots

Flow from CSW prog to fem_prog

unprofs $=$ unprof ${ }^{*} \mathrm{csw} \_$prog

unprofo

Flow from CSW out to fem out

unprof6 $=$ unprof ${ }^{*} \mathrm{csw}$ out

unprof7

Flow from CSW_late_rl to fem_late_rl

unprof $7=$ unprof $^{*} \mathrm{csw}$ _late_rl

unprons

Flow from CSW late $r 2$ to fem late $r 2$

unprof8 $=$ unprof ${ }^{*} \operatorname{csw}$ late_r2

\section{VARIABLES}

Variables defined in terms of compartments, flows etc in the model

alds dead

aids_dead $=$

hivdying_femalesthivdying_malesthivdying_kids

annualCSWcontacts

annualCSW contacts $=\mathrm{cr}$ "clients/csw

cll_prop_prog

cli_prop_prog =

res_cli_prog/(res_cli_progtres_cli_out+0.0001)

clients

clients $=$

cli_immun+cli_early_stcli_late_s+cli_uninftch_prog + cli_1

ate_rl+cli_late_r2+cli_out+cli_early_r

counsel cli

counsel_cli $=(1-$ old_cli_pp)told_cli_pp*counsel

counsel_csw

counsel_csw $=\left(1-0 l d \_c s w \_p p\right)+o l d \_c s w \_p p^{*}$ counselcsw

counsel fem

counsel_fem $=\left(1-0 l d \_f e m \_p p\right)+o l d \_f e m \_p p *$ counsel

counsel_men

counsel_men $=(1-$ old_men_pp $)+o l d \_m e n \_p p *$ counsel

csw

$\operatorname{csw}=$

csw_immun+csw_early_stcsw_late_stcsw_uninf $+c s w \_p r o$

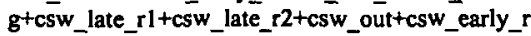

esw_prop_prog

csw prop_prog $=$

res_csw_prog/(res_csw_prog+res_csw_out+0.0001)

fem

fem $=$

fem_immun $+f e m_{-}$early_s + fem_late_s + fem_uninf + fem_late

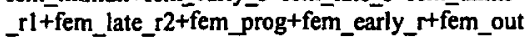

fem prop_prog

fem_prop_prog =

res_fem_prog/(res_fem_progtres_fem_out +0.0001$)$

female_prev_res female prev res $=$

(csw_late_rl+csw_late_r $2+$ fem_late_r $1+$ fem_late_ $r 2+c s w$ early_rtfem_early_r $r$ /females

female_prevalence

female prevalence $=($ females-fem_uninf-csw_uninf-

fem_immun-csw_immun)/females

females

females $=\mathrm{fem}+\mathrm{csw}$

In out1

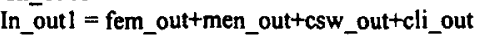

In_out2

In_out2 = fem_out + men_out + csw_out + cli_out $+(1-$

old_fem_pp $)^{*} \overline{\text { fem_late }} \overline{\mathrm{r}} \mathbf{2}+(1-$

old men $\mathrm{pp})^{*}$ men late $\mathrm{r} 2+(1$ -

old_csw_pp)*csw_late_r2+(1-old_cli_pp $)^{*}$ cli_late_r2

In_prog1

In_progl $=$ fem_prog + men_prog $+c s w \_$prog $+c l i \_$prog

In_prog2

In_prog2 =

fem_progtmen_prog+csw_prog+cli prog+old_fem_pp*fe

m_late r2told_men_pp*men_late_r2told_csw_pp ${ }^{*} \mathrm{csw}$ lat e_r2+old_cli_pp*cli_late_r2

\section{Incidence}

incidence $=$

round(inf_cli_immun_stinf_csw_immun_stinf_men_imm un stinf fem immun stinf cli immun $r+i n f$ csw immu n_r rinf_men_immun_rtinf_fem_immun_r+

inf_cli_stinf_csw_stinf_men_stinf_fem_stinf_cli_r+inf_c sw_rtinf_men_rtinf_fem_r+inf_births)

\section{Inf_births}

inf births = round(brate* vtrate*

$w 1$ "csw_early_r+w1*fem_early_ $r+\left(w l^{*} c s w \_e a r l y \_s+w 2 * c\right.$ $s w$ late_stw1 $1^{*}$ fem_early_stw2* fem late_s) $)^{*}($ nevirapine $r$ ate ${ }^{\bar{*}}$ nevirapine_effect+(1-

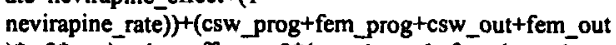
)$^{*} w 2 *$ nevirapine_effect+w2*(csw_late_rl+fem_late_r $\bar{l}+c s$ w_late_r $2+$ fem_late_r 2$)$ ))

\section{male_prev_res}

male prev_res $=$

(cli_late_rì +cli_late_r2+men_late_rl+men_late_r $2+$ cli_earl $y_{-}+{ }^{+}$men_early_r $\left.\mathbf{r}\right) /$ males

male_prevalence

male_prevalence $=$ (males-cli_uninf-men_uninf-

men_immun-cli_immun)/males

males

males $=$ men + clients

marrate2

marrate2 = marrate*men/fem

men

men $=$

men_immun + men_early_s + men_late_s + men_uninf + men_l ate_r1+men_late_r2 + men_prog + men_early_r + men_out

men_prop_prog

men prop_prog $=$

res_men_prog/(res_men_progtres_men_out+0.0001)

milpop

milpop $=$ population $/ 1000000$

non_vaccinated 
non vaccinated $=1$ -

(men_immun+cli_immun+csw_immun+fem_immun)/(men immun+cli_immuntesw_immuntfem_ımmuntmen_uninf †cli_uninf $+\mathrm{csw}$ _uninf $+\mathrm{fem}$ _uninf)

population

population $=$ round $($ males + females $)$

prev_CSW

prev_CSW $=(\operatorname{csw}-\mathrm{csw}$ _uninf-csw_immun $) / \mathrm{csw}$

preval_res

preval_res $=$

(males*male_prev_res+females*female_prev_res)/(males+f emales)

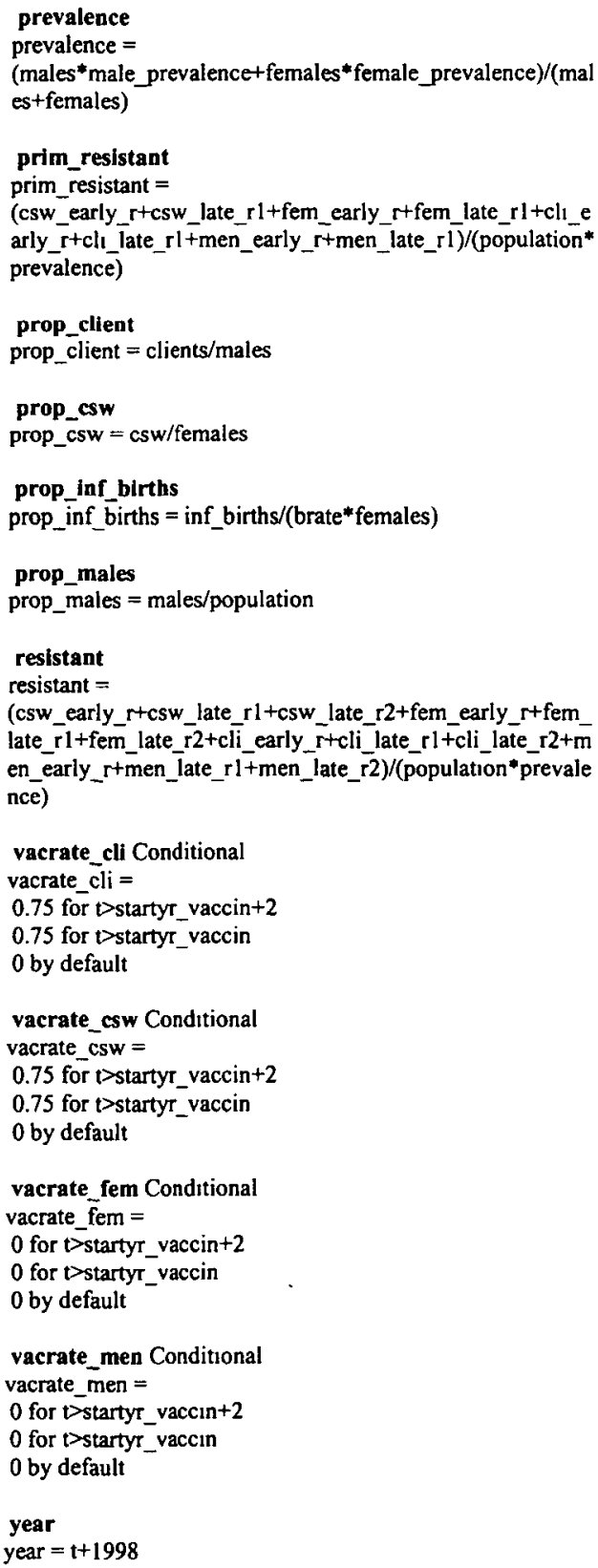

\section{DELAYS}

Time-lagged variables

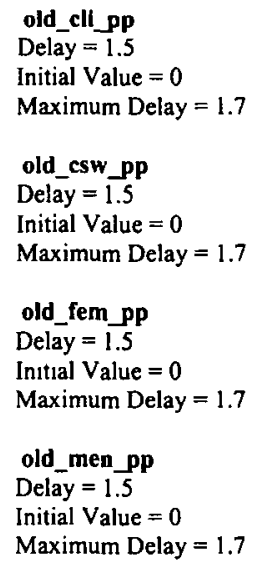

\section{DEFINE VALUES}

Variables influenced by interventions cr

cr $=$ cr_before

nevirapine_rate

nevirapine_rate $=0$

recr_cli_out

recr_cli_out $=0$

recr_cli_prog

recr_cli_prog $=0$

recr_CSW_out

recr_CSW_out $=0$

recr_csw_prog

recr_csw_prog $=0$

recr_fem_out

recr_fem_out $=0$

recr_fem_prog

recr_fem_prog $=0$

recr_men_out

recr_men_out $=0$

recr_men_prog

recr_men_prog $=0$

STD_control

STD_control =

unprot

unprot $=$ unprot_before

\section{INDEPENDENT EVENTS}

\section{Interventions}

\section{STD prog}

Non-periodic triggers at:

startyr_std

Actions:

STD_control = STD_effect; 
Introd_art

Non-periodic triggers at:

startyr_art_intro

Actions:

recr_men_out $=$ art_out_effect;

recr_fem_out $=$ art_out_effect;

recr csw out $=$ art out effect

recr_cli_out $=$ art_out_effect;

Inter HAART pop

Non-periodic triggers at:

startyr_art_pop

Actions:

recr_cli_prog = recr_cli_prog_effect;

recr_fem_prog-recr_fem_prog_effect;

recr_men_prog = recr_men_prog_effect;

recr_men_out $=$ gen_prog_eff"art_out_effect;

recr_fem_out = gen_prog_eff"art_out_effect;

recr_cli_out $=$ gen_prog_eff*art_out effect;

cre-er_after;

Inter HAART CSW

Non-periodic triggers at:

startyr_art_csw

Actions:

recr_csw_prog = recr_csw_prog_effect;

rect_csw_out = gen_prog_eff*art_out_effect;

Inter_CSW

Non-periodic triggers at:

startyr condom CSW

Actions:

unprot $=$ unprot_after;

Inter_MCT

Non-periodic triggers at:

startyr MCT

Actions:

nevirapine_rate $=$ nevirapine _ prop; 



\section{Policy Research Working Paper Series}

Title

WPS2952 The Effects of a Fee-Waiver Program on Health Care Utilization among the Poor: Evidence from Armenia

WPS2953 Health Facility Surveys: An introduction

WPS2954 Never Too Late to Get Together Again: Turning the Czech and Slovak Customs Union into a Stepping Stone to EU Integration

WPS2955 The Perversity of Preferences: The Generalized System of Preferences and Developing Country Trade Policies, 1976-2000

WPS2956 Survey Compliance and the Distribution of Income

WPS2957 Mexico: In-Firm Trainıng for the Knowledge Economy

WPS2958 Globalizatıon and Workers in Developing Countries

WPS2959 Wage Differentials and StatePrivate Sector Employment Choice in the Federal Republic of Yugoslavia

WPS2960 The Poverty/Environment Nexus in Cambodia and Lao People's Democratic Republic

WPS2961 Strategic Plannıng for Poverty Reduction in Vietnam: Progress and Challenges for Meetıng the Localızed Millennıum Development Goals

WPS2962 High Consumption Volatility: The Impact of Natural Disasters?

WPS2963 Catastrophe Insurance Market in the Caribbean Region: Market Failures and Recommendations for Public Sector Interventions

WPS2964 Wages and Productivity in Mexican Manufacturing

WPS2965 Informality Revisited

WPS2966 Health and Poverty in Guatemala

WPS2967 Malnutrition and Poverty in Guatemala
Author

Date

Nazmul Chaudhury

Jeffrey Hammer

Edmundo Murrugarra

Magnus Lindelöw

Adam Wagstaff

Bartlomiej Kaminski

Beata Smarzynska

Çaglar Özden

Eric Reinhardt

Johan A. Mistiaen

Martin Ravallion

Hong Tan

Gladys Lopez-Acevedo

Martin Rama

Michael M. Lokshin

Branko Jovanovic

Susmita Dasgupta

Uwe Deıchmann

Craig Meisner

David Wheeler

Rob Swinkels

Carrie Turk

Philippe Auffret

Philippe Auffret

Gladys López-Acevedo

William F. Maloney

Michele Gragnolati

Alessandra Marini

Alessandra Marini

Michele Gragnolati
January 2003

January 2003

January 2003

January 2003

P. Fiewitt 32724

January 2003

P. Sader 33902

January 2003

H. Tan

33206

January 2003

H. Sladovich 37698

January 2003

P. Sader 33902

January 2003

Y. D'Souza 31449

January 2003

N. Lopez 88032

January 2003

K. Tomlinson 39763

January 2003

K. Tomlinson 39763

M. Geller 85155

January $2003 \quad$ P. Soto 37892

January 2003

M. Gragnolati 85287

January 2003

M. Gragnolati 85287 


\section{Policy Research Working Paper Series}

Title

WPS2968 Refining Policy with the Poor: Local

Consultations on the Draft

Comprehensive Poverty Reduction

and Growth Strategy in Vietnam

WPS2969 Fostering Community-Driven

Development: What Role for the State?

WPS2970 The Social Impact of Social Funds in Jamaica: A Mixed-Methods Analysis of Participation, Targeting. and Collective Action in Community Driven Development

WPS2971 Short but not Sweet: New Evidence on Short Duration Morbidities from India

WPS2972 Economic Growth, Inequality, and Poverty: Findings from a New Data Se

WPS2973 Intellectual Property Rights, Licensıng, and Innovatıon

WPS2974 From Knowledge to Wealth: Transforming Russian Science and Technology for a Modern Knowledge Economy

WPS2975 Policy Options for Meeting the Millennium Development Goals in Brazil: Can Micro-Simulations Help?

WPS2976 Rural Extension Services

WPS2977 The Strategic Use and Potential for an HIV Vaccine in Southern Africa
Jock R. Anderson Gershon Feder

Christopher Desmond

Author

Date

Contact

for paper

Edwin Shanks

Carrie Turk

January 2003

N. Lopez

88032

Monica Das Gupta
Helene Grandvoinnet
Mattia Romanı

January 2003

M. Das Gupta 31983

Vijayendra Rao

Ana María Ibáñez

February 2003

P. Sader 33902

Jishnu Das

Carolina Sánchez-Páramo

February 2003

H. Sladovich 37698

Richard $\mathrm{H}$. Adams, Jr.

February 2003

N. Obias 31986

Guifang Yang

Keıth E. Maskus

February 2003

Alfred Watkins

H. Sladovich
February 2003

Francisco H G. Ferreira

Phillippe G. Leite

February 2003

P. Sader 33902

February 2003

P. Kokila 33716

February 2003 37698

A. Watkins 37277

Robert Greener 